\title{
Mandated restrictions on the use of medically important antibiotics in broiler chicken production in Canada: implications, emerging challenges, and opportunities for bolstering gastrointestinal function and health - a review
}

\author{
Lisa Bean-Hodgins and Elijah G. Kiarie
}

\begin{abstract}
Chicken Farmers of Canada has been progressively phasing out prophylactic use of antibiotics in broiler chicken production. Consequently, hatcheries, veterinarians, and nutritionists have been mandated to contend with less reliance on the use of preventive antibiotics. A topical concern is the increased risk of proliferation of enteric pathogens leading to poor performance, increased mortality, and compromised welfare. Moreover, the gut harbors several taxa such as Campylobacter and Salmonella capable of causing significant illnesses in humans via contaminated poultry products. This has created an opportunity for research and development of dietary strategies designed to modulate gastrointestinal environment for enhanced performance and food safety. Albeit with inconsistent responses, literature data suggest that dietary strategies such as feed enzymes, probiotics/prebiotics, and phytogenic feed additives can bolster gut health and function in broiler chickens. However, much of the efficacy data were generated at controlled research settings that vary significantly with the complex commercial broiler production operations due to variation in dietary, health, and environmental conditions. This review will summarize implications of mandated restrictions on the preventative use of antibiotics and emerging Canadian broiler production programs to meet processor specifications. Challenges and opportunities for integrating alternative dietary strategies in commercial broiler production settings will be highlighted.
\end{abstract}

Key words: alternatives to antibiotics, Chicken Farmers of Canada, broiler gut health, microbiota.

Résumé : L’organisation Les Producteurs de poulet du Canada supprime progressivement l'utilisation prophylactique des antibiotiques dans l'élevage des poulets à griller. Par conséquent, les couvoirs, vétérinaires, et nutritionnistes ont été mandatés à moins se fier aux antibiotiques de façon préventive. Une question d'actualité est le risque accru de prolifération des agents pathogènes entériques qui mènent à une performance pauvre, à une mortalité augmentée, et au bien-être des animaux compromis. De plus, l'intestin abrite plusieurs taxa, comme les Campylobacter et les Salmonella capables de provoquer des maladies importantes chez les humains par contamination des produits de volaille. Ceci a créé une occasion pour la recherche et le développement de stratégies alimentaires conçues pour moduler l'environnement gastro-intestinal pour une meilleure performance et une augmentation de la salubrité des aliments. Malgré des réponses non constantes, les données de la littérature suggèrent que les stratégies alimentaires comme les suppléments alimentaires d'enzymes, les probiotiques/ prébiotiques, et les additifs alimentaires phytogènes peuvent renforcer la santé et la fonction intestinale chez les poulets à griller. Par contre, beaucoup des données sur l'efficacité ont été générées sous des paramètres contrôlés de recherche qui varient de façon importante des opérations complexes commerciales de production de poulets à griller puisqu'il y a des variations dans les conditions alimentaires, environnementales, et de santé. Cette revue résumera les implications des restrictions mandatées d'utilisation préventive des antibiotiques et des programmes émergents de production de poulets à griller au Canada afin de répondre aux spécifications

Received 4 February 2021. Accepted 5 May 2021.

L. Bean-Hodgins. Department of Animal Biosciences, University of Guelph, Guelph, ON N1G 2W1, Canada; New-Life Mills, A Division of Parrish \& Heimbecker, Cambridge, ON N1T 2H9, Canada.

E.G. Kiarie.* Department of Animal Biosciences, University of Guelph, Guelph, ON N1G 2W1, Canada.

Corresponding author: Elijah G. Kiarie (email: ekiarie@uoguelph.ca).

${ }^{*}$ Author E.G. Kiarie served as an Associate Editor at the time of manuscript review and acceptance; peer review and editorial decisions regarding this manuscript were handled by Martin Gierus.

Copyright remains with the author(s) or their institution(s). This work is licensed under a Creative Commons Attribution 4.0 International License (CC BY 4.0), which permits unrestricted use, distribution, and reproduction in any medium, provided the original author(s) and source are credited. 
des transformateurs. Les défis et opportunités d'intégration de stratégies alimentaires alternatives dans les environnements commerciaux de production de poulets à griller seront mis en évidence. [Traduit par la Rédaction]

Mots-clés : alternatives aux antibiotiques, Les Producteurs de poulet du Canada, santé intestinale des poulets à griller, microbiote.

\section{General Introduction}

The Chicken Farmers of Canada (CFC) 2019 Annual Report shows a steady increase in the per capita consumption of chicken from 2016 to 2019 with chicken being the number one meat protein chosen by consumers. A strong increase $(2.5 \%)$ in chicken production was reported in 2019 with Canadian farmers producing 1297.6 million $\mathrm{kg}$ of chicken (CFC 2019). Although chicken remained the number one meat protein chosen by consumers in 2020, consumption decreased by $0.7 \mathrm{~kg}$ per person and chicken production decreased by $2.0 \%$ compared with 2019 due to the COVID-19 pandemic (CFC 2020). Canadian chicken production is unique in that the supply of chicken is managed by a quota system (Heminthavong 2015). The quota system ensures that the correct amount of chicken is produced accurately representing the demand. This prevents a surplus of chicken from being marketed while ensuring processors receive the correct amount of product and producers are paid a fair price. As of today, there are 2837 producers across Canada producing broiler chicken under the direction of CFC and the supply management system (CFC 2020). In addition to maintaining the supply management system, CFC also has a responsibility to develop programs that support sustainability, trust, animal welfare, and biosecurity within the poultry industry. As a result of their commitment to consumers, CFC successfully implemented the National Antimicrobial Use Strategy (AMU) in 2019. This strategy mandated that the poultry industry would no longer use category I or II antimicrobials in poultry feed or water for prophylaxis. As the industry moves away from the preventative use of antibiotics, new broiler production programs have emerged with varying degrees of antibiotic restrictions. The objective of the present review is to characterize recent and immediate future CFC mandated restrictions on preventive use of antibiotics, explore implications on broiler chicken production and challenges of merging broiler production programs. The review will also appraise alternative feeding strategies for maintaining a functional and healthy gastrointestinal tract (GIT) in the context of commercial production conditions.

\section{State of Broiler Industry in Canada: Historical Overview}

The Canadian broiler industry provides consumers with nutritious, affordable, and high-quality meat protein for their diets. Broiler chicken producers rely on industry veterinarians, nutritionists, processors, and hatcheries to ensure their birds are grown with efficiency, sustainability, and the highest standard of animal care. The Canadian broiler chicken industry has seen an overhaul to its Codes of Practice leading to increased focus on health, welfare, environment, and emergency management. Perhaps the biggest change has been the increased awareness associated with antimicrobial resistance and the phasing out of critically important antimicrobials for growth promotion and disease prevention. In Canada, antibiotics are categorized by their importance relative to human medicine. The four main categories are based on the ability of an antibiotic to effectively treat a human infection. Products or their analogs found in categories I, II, and III are classified as having some level of importance to humans (Table 1). In 2012, the poultry industry began to implement timelines regarding a strategic plan to ban the use of medically important antibiotics for preventative use. The implementation of the phasing out of these antibiotics is ongoing and continues to be a milestone in the history of broiler production in Canada. Chemical coccidiostats also used to prevent coccidiosis are permitted in poultry feed but are not classified as antibiotics. Commercial broiler programs in Canada will utilize antibiotics categorized as per Table 1 to various extents depending on the requirements governed by the processors (CFC 2018).

\section{Historical Use of Antibiotics as Growth Promoters (AGP)}

An antibiotic growth promotor (AGP) is defined as an antibiotic added to feed at low subtherapeutic levels for the purpose of improving growth and feed efficiency (Niewold 2007). The use of AGP in poultry diets was discovered in 1942 at the University of California by E.L.R Stokstad and Thomas H. Jukes. One of the first published papers involved the addition of sulfasuxidine, streptothricin, and streptomycin to poultry diets where an increased growth response was reported in conjunction with a reduction in cecal coliform bacteria in 4-wk-old chicks (Moore and Evenson 1946). The effects of AGP on growth performance, feed efficiency, and intestinal physiology are well documented throughout the 1950s (Groschke and Evans 1950; Stokstad and Jukes 1950; Pepper et al. 1953; Jukes et al. 1956; Dibner and Buttin 2002). The first reports of antibiotic-resistant bacteria also became apparent in the 1950s (Diaz-Sanchez et al. 2015). However, in 1951, the Food and Drug Administration (FDA) approved the use of antibiotics in feed without a veterinary prescription, setting the stage for a wide use of antibiotics in poultry feed for the next 50 yr (Jones and Ricke 2003). Antibiotics were effective 
Table 1. Categories of antibiotics in Canada.

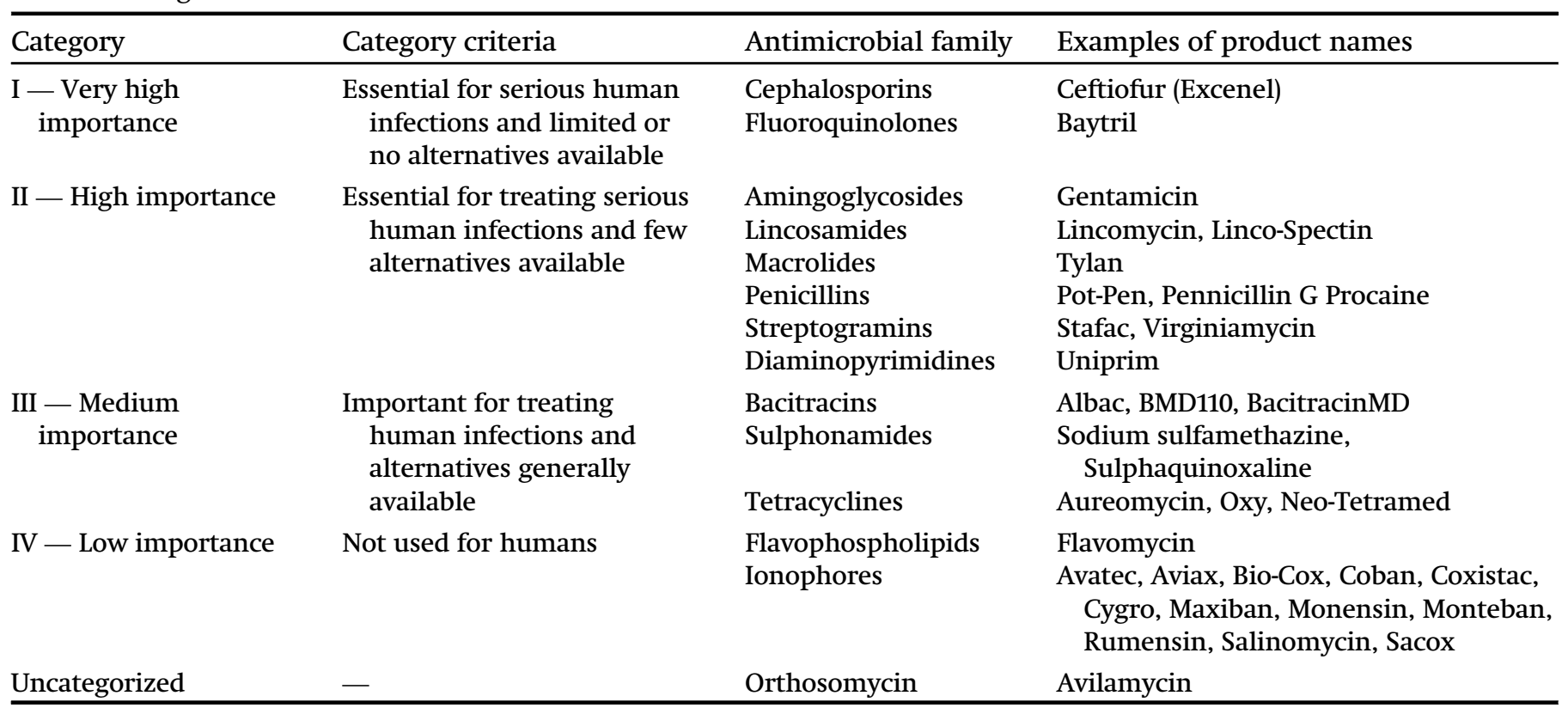

Note: Information obtained from CFC 2018.

in producing growth performance response year after year, regardless of the type of ingredients used in the feed (Dafwang et al. 1984). This was important as the broiler industry was growing rapidly, and there was a need to supply the demand for chicken. Although selective breeding helped improve feed efficiency and meat yields to a great extent, the use of antibiotics also contributed to improved performance. The benefits of dosing birds with low levels of antibiotics in feed continued to be documented throughout the 1960s (Eyssen 1962; Combs and Bossard 1963; Eyssen and De Somer 1963). These benefits made AGP an essential component of modern broiler production throughout the years and still today.

\section{Mode of Action}

Antibiotic growth promoters have been used extensively to prevent intestinal issues amplified by enteric infections (Ducatelle et al. 2018). Although the exact mechanism by which AGP work is not fully understood, the basis of their mode of action involves the management and modification of microflora in the digestive tract (Coates et al. 1963; Gaskins et al. 2002; Niewold 2007). Different antibiotics will vary regarding their overall chemical and physical structures, but many will have a similar mode of action. The mode of action of the antimicrobials available in the Canadian poultry production is listed in Table 2. Researchers hypothesize that the performance benefits associated with the use of AGP could be caused by the suppression of bacteria that under normal conditions would cause malabsorption of nutrients such as fat, protein, carbohydrates, vitamins, and minerals (Eyssen and De Somer 1963). With the suppression of bacteria, competition for nutrients between bacteria and host is decreased, and there is a decrease in the production of performance reducing metabolites (Dibner and Richards 2005; Khodambashi Emami et al. 2012). The performance benefits associated with the addition of antibiotics is not dependent on sex, diet composition, environment, or class of antibiotic, meaning that the addition of antibiotics will cause some degree of improved growth performance regardless of these factors (Biely and March 1959; Goatcher and McGinnis 1972; Miles et al. 2006). The performance benefits associated with the modification of microflora in the digestive tract are further supported by work done with germ-free broiler chickens. In germ-free birds, feeding antibiotics did not result in improved growth performance (Coates et al. 1963). The lack of response to antibiotics in germ-free birds can be explained by the fact that the microbial population is not present. Therefore, the antibiotic has no bacteria to target or suppress in germ-free animals, further validating the mode of action as being a modification of microflora.

In addition to working to inhibit bacteria and prevent disease, antibiotics improve performance, feed efficiency, protein digestibility, and meat yield (Gaskins et al. 2002; Afsharmanesh et al. 2013; Wang et al. 2016). Antibiotics can influence performance by supporting intestinal structural integrity (Cao et al. 2013; Hutsko et al. 2016; Jayaraman et al. 2017; Elhassan et al. 2018). If intestinal integrity is compromised, the effectiveness of digestion and absorption is suboptimal, thereby leading to reduced growth performance. Research has proven a link between gut morphology and overall performance (Lei et al. 2013). The more developed the gut, the 
healthier the animal, and consequently, more efficient nutrient utilization leading to better performance. The intestinal surface is lined with finger-like projections called villi that are designed to increase the surface area which fosters efficient digestion and absorption of nutrients. Scientists often focus on the villi lining the duodenum, jejunum, and ileum with particular attention on the jejunum as it is the main site for digestion and absorption of starch, protein, and fat (Oso et al., 2019). Improvements in growth performance parameters are linked to longer villus height and a higher villus: crypt depth ratio which is an index of digestive and absorptive capacity (Lei et al. 2013; Jayaraman et al. 2017). Villus height is measured from the top of the villus to the villus crypt (Elhassan et al. 2018). Crypt depth is measured from the base of the villus to the lamina propria (Cao et al. 2013). Growth performance is improved in birds with shorter crypt depth (Wang et al. 2015). A ratio can then be calculated by dividing the villus height by the crypt depth. A high ratio is indicative of good gut health, whereas a low ratio could indicate poor nutrient absorption and decreased performance (Xu et al. 2003). Villus height can be influenced by diet and the type of antimicrobials used in feed formulation (Miles et al. 2006; Baurhoo et al. 2009). It has been reported that birds fed virginiamycin have shorter ileum villus height and crypt depth compared with birds fed bacitracin methylene disalicylate (Miles et al. 2006). Baurhoo et al. (2009) did not report a difference in the villus height recorded from the duodenum, jejunum, or ileum of broilers fed virginiamycin or bacitracin.

Including antimicrobials in a diet is widely recognized to cause thinning and decrease the weight of the small intestine (Coates et al. 1955; Jukes et al. 1956; Miles et al. 2006; Wang et al. 2019a). The thinning of the gut wall in response to antibiotics is thought to be caused by loss of mucosal cell proliferation. This may be because of a change in the microbial population and, therefore, a reduction of short-chain fatty acids (SCFA) which are known to support epithelial development (Frankel et al. 1994). It has been hypothesized that the reduced weight of the small intestine facilitated the transport of nutrients across the intestine leading to improved performance (Coates et al. 1955; Eyssen and De Somer 1963; Miles et al. 2006). However, the opposite has also been found where a decreased intestinal weight was reported with no increase in performance in birds fed antibiotics (Izat et al. 1989). Researchers have also concluded that while the overall relative weight of the small intestine may be consistent, reducing the weight and length of the duodenum favors increased weight and length of the jejunum which may be associated with enhanced nutrient digestibility as the jejunum is the main site of the absorption of nutrients (Reis et al. 2017).

An elevated growth response was reported in a wheatbased diet supplemented with antibiotics compared with a corn-based ration, implying that while the effect of an antibiotic on growth performance is consistent regardless of diet, the extent of the growth performance response can be influenced by the types of ingredients used in the diet (Johnston and Arscott 1974). Ingredients such as wheat, rye, barley, raw beans, and lentils are known to limit growth because they all contain antinutritional factors (ANFs) that can make birds more vulnerable to enteric diseases. The antibiotic-induced growth response in birds fed diets containing ingredients high in ANF is hypothesized to be caused by the antibiotic ability to influence and stabilize the gut microflora (MacAuliffe and McGinnis 1971; Goatcher and McGinnis 1972). The ability of antibiotic supplementation to overcome ANF and the negative effects caused by viscous grains has been well documented (Marquardt et al. 1979; Antoniou and Marquardt 1982). Protein digestibility has been shown to be significantly improved in wheat-based diets supplemented with antibiotics. This enhanced digestibility led to improved body weight gain and feed efficiency (Afsharmanesh et al. 2013). Feeding raw beans has been known to decrease growth in broiler chicks; however, the addition of antibiotics to the same diet can overcome this negative effect (Goatcher and McGinnis 1972). Consequently, the use of AGP has made it possible to formulate diets containing ingredients that would otherwise be problematic and potentially growth limiting. This has allowed nutritionists to use suboptimal and potentially less expensive ingredients in feeds while maintaining performance. Without the use of AGP, the focus on ingredient type, quality, and digestibility becomes increasingly important.

\section{Current and Emerging Concerns Regarding the Use of AGP}

Concern surrounding antimicrobial resistance stemming from the continuous use of antibiotics is mentioned throughout history with the issue hitting a bigger stage in the 1990s. The primary concern is that antibiotics used in human medicine are no longer as effective in the treatment of diseases and that one of the perceived factors leading to the resistance was the use of antibiotics in food-producing animals (Castanon 2007; Seal et al. 2013; Diarra and Malouin 2014). The European Union (EU) was quick to remove tetracyclines and procaine penicillin as growth promoters in 1972-1974, whereas they remained available in the United States (Bywater 2005). In the 1990s, the EU further banned several of the most common poultry AGP such as virginiamycin and zinc bacitracin, whereas they remained available in North America (Bywater 2005). Antibiotics other than coccidiostats and histomonostats were further banned in the EU as of 1 Jan. 2006 (Castanon 2007). Although the EU was very aggressive in their timelines on the elimination of antimicrobials, during the same time, the United States was much slower in adopting a reduction timeline. As of 2005, the United States did not have a regulatory mandate for 
Table 2. Classes and mode of action of antimicrobials used in Canadian animal agriculture.

\begin{tabular}{|c|c|c|c|}
\hline Antimicrobial family & $\begin{array}{l}\text { Category of } \\
\text { importance relative to } \\
\text { human medicine }\end{array}$ & Mode of action & Reference \\
\hline Cephalosporins & I & $\begin{array}{l}\text { Inhibit cell wall synthesis and } \\
\text { stops cell growth }\end{array}$ & Ghuysen et al. 1979 \\
\hline Quinolones & I & Inhibits DNA replication & $\begin{array}{l}\text { Georgopapadakou et al. 1989; } \\
\text { Drlica et al. } 2008\end{array}$ \\
\hline Aminoglycosides & II & Inhibits protein synthesis & Udumula et al. 2013 \\
\hline Lincosamides & II & Inhibit protein synthesis & Tenson et al. 2003 \\
\hline Macrolides & II & Inhibits protein synthesis & Tenson et al. 2003 \\
\hline Penicillins & II & $\begin{array}{l}\text { Inhibits cell wall synthesis. } \\
\text { Disrupts crosslinking in } \\
\text { cell wall leading to cell } \\
\text { death }\end{array}$ & Kaufmann 1964; Oka 1976 \\
\hline Streptogramins & II & Inhibits protein synthesis & Tenson et al. 2003 \\
\hline Diaminopyrimidines & II & Inhibits folate synthesis & $\begin{array}{l}\text { Bockstael and Van Aerschot } \\
2009\end{array}$ \\
\hline Bacitracins & III & Inhibits cell wall synthesis & $\begin{array}{l}\text { Bockstael and Van Aerschot } \\
\text { 2009; Sugimoto et al. } 2017\end{array}$ \\
\hline Sulphonamides & III & Inhibits folate synthesis & $\begin{array}{l}\text { Bockstael and Van Aerschot } \\
2009\end{array}$ \\
\hline Tetracyclines & III & Disrupts protein synthesis & Brock 1963 \\
\hline Flavophospholipids & IV & Inhibits cell separation & Sugimoto et al. 2017 \\
\hline Ionophores & IV & $\begin{array}{l}\text { Disrupts cation transport } \\
\text { across the cell membrane }\end{array}$ & $\begin{array}{l}\text { Běhal 2006; Chapman et al. } \\
2010\end{array}$ \\
\hline Orthosomycin & Uncategorized & Disrupts protein synthesis & $\begin{array}{l}\text { Kofoed and Vester 2002; } \\
\text { Krupkin et al. } 2016\end{array}$ \\
\hline
\end{tabular}

AGP removal; however, consumer pressure was mounting regarding reducing the use in poultry production (Dibner and Richards 2005). In 2012, the FDA provided a framework for the voluntary implementation of practices to promote veterinary oversite and judicious use of antibiotics considered to be important to human medicine (Greer 2016). In 2017, the FDA mandated the removal of antibiotics for growth promotion. While producers continued to use medically important antimicrobials for the prevention of disease (Patel et al. 2020). The Canadian poultry industry has been modest compared with the EU in its approach to reducing antimicrobial use while being more aggressive than the United States in their mandated reduction timelines.

\section{Mandated CFC Restrictions and Emerging Production Programs}

Antibiotics and anticoccidials have always been readily available as feed ingredients to prevent the onset of diseases such as necrotic enteritis (NE) and coccidiosis. Consequently, the Canadian poultry industry has relied heavily on medicating ingredients to support flocks and maintain production efficiency under all conditions and diet types. However, CFC is very focused on issues surrounding antimicrobial resistance. In 2014, the preventative use of category I antibiotics in the hatchery, feed, and water was eliminated for Canadian raised broiler chickens. This was followed by a very definitive and proactive antimicrobial reduction strategy in January 2019 that implemented phase 1 with the elimination of the preventative use of category II antibiotics at the hatchery, in feed and water. The goal was to reduce the reliance on antibiotics by phasing out their use for prophylaxis and increasing surveillance of antibiotic use across the country. Phase 2 does not have a definitive date for implementation but will impose the elimination of the preventative use of category III antibiotics. This strategy will allow the use of ionophores and the use of antibiotics for the treatment of disease when diagnosed and prescribed by a licensed veterinarian (therapeutic use). Although the Canadian feed industry has seen an increase in veterinary oversight, several medical ingredients are approved as feed additives and remain as options for poultry producers with or without a veterinary prescription (Table 3). However, with increased emphasis on reducing the use of antibiotics, new Canadian markets have emerged where the processor defines the antibiotic program, and birds are marketed with various claims associated with antibiotic use. Canadian producers can raise broilers on the following programs:

- Conventional: categories III and IV antibiotics and avilamycin permitted. 
Table 3. Approved medicated ingredients for broiler chickens.

\begin{tabular}{|c|c|c|c|}
\hline Item & Product & Category & Active ingredient \\
\hline \multirow{11}{*}{$\begin{array}{l}\text { Prevention of } \\
\text { coccidiosis }\end{array}$} & Aviax Medicated premix & Ionophore & Seduramicin sodium \\
\hline & Monensin & Ionophore & \\
\hline & Rumensin & Ionophore & \\
\hline & Coxistac $6 \%$ & Ionophore & Salinomycin sodium \\
\hline & Salinomycin 60 & Ionophore & \\
\hline & Biocox 120 & Ionophore & \\
\hline & Maxiban & Ionophore and Chemical & Narasin and nicarbazin \\
\hline & Monteban & Ionophore & Narasin \\
\hline & Clinacox $0.5 \%$ & Chemical & Diclazuril \\
\hline & Zoamix & Chemical & Zoalene \\
\hline & Deccox 6\% Premix & Chemical & Decoquinate \\
\hline \multirow{5}{*}{$\begin{array}{l}\text { Prevention of necrotic } \\
\text { enteritis }\end{array}$} & BMD 110 & - & Bacitracin methylene disalicylate \\
\hline & BacitracinMD & - & \\
\hline & Albac110 Zinc Bacitracin Premix & - & Zinc bacitracin \\
\hline & Zinc Bacitracin 110 & - & \\
\hline & Surmax & - & Avilamycin \\
\hline $\begin{array}{l}\text { Improved weight gain } \\
\text { and feed efficiency }\end{array}$ & Flavomycin 4 antibiotic premix & - & Bambermycin \\
\hline
\end{tabular}

Note: Information obtained from Canadian Food Inspection Agency 2020.

- Raised without antibiotics of human importance: No categories I, II, or III antibiotics for prevention. Only avilamycin and category IV antibiotics are permitted for the prevention of coccidiosis and NE.

- $\quad$ Raised without the use of antibiotics (RWA): No categories I, II, III, or IV antibiotics permitted for prevention. It should be noted that in Canada ionophores are categorized as a category IV antibiotic and are not permitted in an RWA program. However, chemical coccidiostats are not antimicrobials, and therefore, they are not an antibiotic and are permitted in any of these programs.

\section{Challenges of Raising Broiler Chickens with Restricted Antibiotics Use in Canada}

Intestinal diseases have continued to plague the modern broiler chicken since their domestication and the implementation of intensive farming. These diseases are an important concern because they lead to reduced performance, increased mortality, and lost profits (Chan et al. 2015; Blake et al. 2020). The prophylactic use of antibiotics including ionophores, chemical coccidiostats, and AGP have been effective tools in protecting chickens from the onset of intestinal diseases such as coccidiosis, NE, and dysbiosis (disruption in the balance of the microbiota). The primary concerns with antibioticfree/reduced feeding programs are increased incidences of enteric diseases causing impaired nutrient digestion and absorption ultimately leading to poor feed efficiency, increased mortalities, more condemnations, and a negative impact on animal welfare (Xu et al. 2003; Gaucher et al. 2015; Kiarie et al. 2019). Damage from Gram-negative bacteria leading to diseases such as colibacillosis, yolk sac infection, and enterococcus are more likely to require therapeutic antibiotic administration to treat the onset of disease. In addition to the challenges surrounding bird health, there are also concerns surrounding food safety. With the removal of antibiotics, there are questions regarding the potentially elevated levels of bacteria on poultry meat that could be a risk for foodborne illness in humans (Van Immerseel et al. 2004; Golden and Mishra 2020).

\section{Necrotic Enteritis}

Necrotic enteritis is an enteric disease caused by the Gram-positive bacteria Clostridium perfringens commonly occurring between 2 and 6 wk of age with the highest risk for onset occurring around $3 \mathrm{wk}$ of age (Moore 2016; Broom 2017; Hofacre et al. 2018). Predisposing factors such as breed, age, diet, gut $\mathrm{pH}$, environment, viral infections, biosecurity, and stress may trigger the proliferation of bacteria that damages the intestine and leads to clinical NE infection (Annett et al. 2002; Allaart et al. 2013; Moore 2016). Symptoms of a clinical NE infection 
include loose droppings, necrotic intestinal lesions, reduced growth rate, poor feed efficiency, and high mortality (Broom 2017). A subclinical infection is more subtle, with reduced performance and higher carcass condemnations at processing. Birds experiencing a subclinical challenge are estimated to have a $12 \%$ reduction in body weight and $10.9 \%$ increase in feed conversion compared with healthy birds (Skinner et al. 2010). This level of reduced performance represents a significant financial loss to producers (Chan et al. 2015). Antibiotics have been proven to be effective in delaying and controlling the onset of a $C$. perfringens infection as well as reducing cecal Escherichia coli and Campylobacter concentration (Baurhoo et al. 2009; Fasina et al. 2016). Consequently, the poultry industry continues to use antibiotics to control $C$. perfringens to prevent the incidence of NE (Stanley et al. 2014a).

\section{Coccidiosis}

Avian coccidiosis is caused by a protozoan parasite belonging to the genus Eimeria (Chapman 2014). Coccidia can invade multiple points within the digestive tract that can cause the damage needed to facilitate NE. Coccidia are present wherever chickens are raised, making the modern broiler chicken especially vulnerable to infection due to intensive farming and the fact that broilers are reared on the floor and not in cages. The negative effects on average daily gain, feed conversion, and mortality in broilers challenged with coccidiosis are clearly defined (McDougald 1998; Scheurer et al. 2013). Birds suffering from a severe cocci challenge may show symptoms including dehydration, depression, ruffled feathers, off-feed, and bloody droppings (Bains 1980). The onset of avian coccidiosis can be prevented by the application of ionophores and chemical coccidiostats in feed/water. However, robust vaccination programs have been developed whereby live oocysts are administered to chicks at the hatchery in a low dose (Chapman 2014; Ritzi et al. 2016). This allows birds to develop their own immunity protecting them from a coccidiosis challenge later in their life cycle.

\section{Dysbiosis and Stability of the Microbiota}

Within the GIT resides an assortment of microorganisms that make up the microbiota including, viruses, bacteria, fungi, and protozoa. The avian microbiota refers specifically to the diverse bacterial community and multitude of microbes that reside in the GIT (Roto et al. 2015; Kogut 2019). The term microbiome refers to the microbiota plus the genetic material found in an environment (Roto et al. 2016). The complex mechanisms of the microbiome and the corresponding interactions with the host cannot be ignored as their metabolic activity has been equated to the functionality of an organ within an organ, making this community a key factor in maintaining intestinal homeostasis (Kogut 2019). In this respect, the gut is an interconnecting network of ecosystems composed of the intestinal epithelium, gut immune system, and the microbiota (Kogut 2013).

The GIT of broiler chickens is home to more than 100 billion bacteria comprised over 900 different species (Stanley et al. 2014a; Borda-Molina et al. 2018; Yadav and Jha 2019). Amit-Romach et al. (2004) focused on six main bacterial groups in the chicken GIT which were classified as beneficial bacteria (Lactobacillus and Bifidobacteria), harmful bacteria (E. coli and Clostridium), or inconsequential to the host but pose a risk to human health (Salmonella and Campylobacter). Each section of the GIT is colonized by different but highly interconnected bacterial populations (Borda-Molina et al. 2018). The bacterial residents of each section are adapted to the specific environment, host physiology, and available nutrients present in that portion of the GIT (Apajalahti and Vienola 2016). Each section of the GIT houses a unique bacterial profile and while many species have been identified, there remains many yet to be cultured. A review by Stanley et al. (2014a) reported that Lactobacillus was the dominant and most abundant bacteria in all sections of the chicken GIT. In addition to the Lactobacillus spp., the ileum was found to harbor Streptococcus, Coliforms, Enterobacteriaceae, Clostridiaceae, and the cecum was reported to be rich in unknown species of Lactobacillus, Bacterioides, Clostridium, and Bifidobacterium (Stanley et al. 2014a). Escherichia coli and Clostridium are detectable in both the duodenum and the ileum and are found at low levels within the GIT of healthy birds throughout their lifetime (Amit-Romach et al. 2004).

The different species of bacteria residing in the sections of the GIT play various roles and are influential in overall bird performance and health (Kollarcikova et al. 2019). Bird performance and health benefits are the results of the bacterial community's ability to carry out four main classes of interactions including the exchange of nutrients, influence immune function, pathogen control, and the development of the digestive system (Clavijo and Florez 2018). Chickens originating from the same flock have similar microbial diversity compared with flocks from other farms (Kollarcikova et al. 2019). These bacterial populations can be manipulated by diet, stress, biosecurity, geography, seasonality, environment, litter, and age of the birds (Clavijo and Florez 2018; Oakley et al. 2018; De Cesare et al. 2019). An alteration or shift in the diversity of a bacterial population can lead to the condition known as dysbiosis. Dysbiosis is a condition where the co-existence between host animal and microbiome becomes unbalanced (Yan et al. 2017). If dysbiosis occurs in the microbiome proper immune function could be compromised (Kogut 2017).

Beneficial bacteria such as Lactobacillus and Bifidobacteria living in the small intestine and cecum of broiler chickens are known to help increase enzyme activity, they compete with pathogens for the same resources and prevent colonization via competitive 
exclusion thereby maintaining balance within the microbiome. Lactobacillus species found in the crop are hypothesized to play a role in breaking down starch and the fermentation of lactate (Clavijo and Florez 2018). Bacteria such as E. coli and Clostridium are found at low levels in the gut of healthy birds throughout their life span. At $25 \mathrm{~d}$ of age, E. coli and Clostridium were detectable in both the duodenum and the ileum (Amit-Romach et al. 2004). When provided with an ideal opportunity to proliferate and thrive, these bacteria can lead to significant disease challenges in poultry. One of the most problematic diseases in commercial poultry today is avian colibacillosis caused by enterotoxigenic E. coli (Wang et al. 2017). Birds diagnosed with this disease often experience high mortality and need to be treated with antibiotics.

\section{Processing and Food Safety Concerns}

The use of antibiotics over consecutive periods can lead to reduced efficacy of the antibiotic. This could be caused by a change in microbial populations as a result of suppressing specific types of bacteria while making the animal vulnerable to other bacterial infections. It has been hypothesized that using the same antibiotic over consecutive flocks can lead to an unbalanced microbiota whereby some beneficial bacteria are inhibited. This may result in a loss of performance-enhancing metabolites normally produced by beneficial bacteria that would benefit the host animal (LaVorgna et al. 2013). Consequently, it has become an industry practice to rotate antibiotics between flocks to prevent the continuous use of the same antibiotic over consecutive periods. Due to the phasing out of many antibiotic options for commercial broilers, it will soon become common to use the same antibiotic over consecutive periods. Therefore, the industry is faced with either the possible loss in efficacy of antibiotics or their complete removal from flocks. Processors are faced with some possible challenges associated with the removal of AGP including decreased body weight and reduced flock uniformity; however, increased condemnations may not necessarily occur (Engster et al. 2002; Smith 2011; Gaucher et al. 2015; Parent et al. 2020). The degree of challenges experienced at processing will be dependent on the occurrence and severity of clinical and subclinical enteric diseases (Kaldhusdal et al. 2016).

Food safety concerns may also be associated with the removal of AGP as it has been reported that the prevalence of foodborne pathogens posing a risk to human health may differ in poultry products reared under alternative production systems (Heuer et al. 2001; Bailey and Cosby 2005). Salmonella and Campylobacter are common pathogens found in poultry products known to cause foodborne illness in humans (Golden and Mishra 2020). Some strains of $C$. perfringens also produce an enterotoxin that can cause illness in humans (Van Immerseel et al. 2004). Although it is certain that poultry products do contain these potential pathogens, it is unclear whether poultry grown under different production systems such as organic, free-range, or RWA contain more risk than conventional systems (Bailey et al. 2019; Golden and Mishra 2020). More research is required to evaluate the risk for foodborne illness in humans as a result of rearing broilers under different production systems with or without the use of AGP.

\section{Complicity of Evolving Dietary Composition}

Nutritionists are tasked with formulating "gut friendly" diets taking into consideration highly digestible ingredients and ideal nutrient levels for optimal growth and feed efficiency (Choct 2009). Although broiler chickens are highly efficient in converting feed to food products, they still excrete significant amounts of undigested nutrients. For example, broilers lose almost $25 \%-30 \%$ of ingested dry matter, $20 \%-25 \%$ of gross energy, $30 \%-50 \%$ of nitrogen, and $45 \%-55 \%$ of phosphorus intake in the manure (Ravindran 2012). The consequences of variable and low nutrient digestibility range from economic (i.e., through increased feed costs, proliferation of pathogens in the gut, poor feed efficiency) to ecological (i.e., through nutrient loading and emissions into the environment). (Kiarie et al. 2013; Kiarie et al. 2016). Moreover, undigested feed components increase visceral weight, consequently increasing utilization of dietary energy and amino acids for maintenance at the expense of tissue deposition (growth) (Cant et al. 1996; Agyekum et al. 2012). Therefore, the types of ingredients and nutrients provided in a diet can influence the stability of the microbiota, and the overall composition of feed is an important consideration when trying to maintain a healthy gut environment.

\section{Feed Protein}

In monogastric nutrition, protein (amino acids) is the second most expensive component of the feed after energy. Different protein sources and concentrations in the diet contribute varying amounts of indigestible nitrogen at the terminal ileum (Bryan et al. 2019). High protein diets have been found to influence the ceca microbiota and have been reported as a trigger for enteric diseases (Stanley et al. 2014b; Broom 2017; De Cesare et al. 2019; Haberecht et al. 2020). Undigested protein in the terminal ileum increases the amount of nitrogen available for bacteria residing in the hindgut which is subject to fermentation and the production of toxic compounds that negatively affect the host (Apajalahti and Vienola 2016; van der Aar et al. 2017). Administration of fish meal proteins in broiler chickens feeding program led to a sharp increase in the concentrations of $C$. perfringens and necrotic lesions in the intestinal mucosa (Drew et al. 2004). The inclusion of meat and bone meal has been shown to increase the population of $C$. perfringens in the ileum and ceca of broiler chickens (Wilkie et al. 2005). The inclusion of animal 
proteins in the absence of antibiotics may predispose birds to enteric diseases like NE (Zanu et al. 2020).

As such, there is a perception in the industry that animalderived proteins predispose birds to gastrointestinal disturbances. This has led to the development and promotion of all-vegetable protein formulation for birds raised without antibiotics and in organic broiler production. However, birds fed an all-vegetable diet have been found to consume more water and produce more excreta leading to increased litter moisture and increased incidence of footpad dermatitis (Vieira and Lima 2005; Eichner et al. 2007). A reduced growth rate has been reported when birds are fed an all-vegetable diet compared with the same diet containing animal proteins (Wisman et al. 1954). The performance of commercial flocks on an all-vegetable diet using conventional antibiotics has not been compared with the same diets containing animal proteins (Smith 2011). However, it appears that feed protein source and quantity may have a significant impact on the intestinal microbiota, both qualitatively and quantitatively (Parenteau et al. 2020; Kiarie et al. 2021). Therefore, it is very important for nutritionists to pay particular attention to the types of protein ingredients used in feed so that they are aware of any possible impact on immune function and microbiome diversity (Choct 2009).

From the viewpoint of animal health, it is interesting that there seems to be a link between enteric pathogens and certain feed protein sources. Adjusting protein supply and amino acid profiles can be considered as essential to achieve optimal performance and to control the intestinal formation of metabolites such as ammonia and biogenic amines from protein fermentation that are generally considered as detrimental (Nyachoti et al. 2006; Heo et al. 2013; Parenteau et al. 2020; Kiarie et al. 2021). The use of supplemental amino acids would offset or minimize the need to use some proteins, which could reduce the cost of feeds. Furthermore, extensive use of supplemental amino acids would allow nutritionists to more precisely meet the animals' dietary requirements while reducing dietary crude protein. This change in formulation can positively impact gut health and the environment by reduction of environmental excretion of nitrogen and reduce metabolic stress of detoxifying nitrogen catabolites.

\section{Non-starch Polysaccharides}

Diets containing high levels of wheat, rye, and barley are known to be detrimental to gut health resulting from high levels of non-starch polysaccharides (NSP) content within these grains. The NSPs in these grains have been shown to decrease feed intake, reduce growth rate, and compromise the digestion and absorption of all nutrients (Antoniou et al. 1981; Brenes et al. 1993). The effects of these ingredients are so detrimental to gut health that they have been used in challenge models to cause intestinal inflammation, modification of intestinal viscosity, and trigger dysbiosis (Tellez et al. 2014; Chen et al. 2015; De Meyer et al. 2019). Non-starch polysaccharides are components of the cell wall that are categorized into two groups which are indigestible by the bird's own endogenous enzymes and exhibit different forms of antinutritional effects when incorporated into a diet. Soluble NSP are known to promote increased digesta viscosity, whereas insoluble NSP are known to impair nutrient digestibility (Dusel et al. 1998; Smeets et al. 2018; Musigwa et al. 2021). When fed to poultry, NSP will compromise overall performance while making the bird more vulnerable to enteritis and gut health infection due to an increase in digesta viscosity inhibiting the efficient breakdown and absorption of nutrients combined with an overgrowth of the gut microflora (Choct et al. 1999; Latorre et al. 2015; Broom 2017; Yan et al. 2017). In the absence of antibiotics, it is important to minimize ingredients that are less digestible and that are known to be a precursor for gut health infections (Cervantes 2015). Younger birds may be less tolerant to poorer quality less digestible ingredients making young meat birds sensitive to feed formulation (Loar et al. 2010).

\section{Enzyme Inhibitors}

Soybeans, peas, and legumes are common plant-based protein sources known to contain the enzyme inhibiting ANF, trypsin inhibitor (TI). Soybean meal is the most concentrated source of TI and one of the most important plant-based protein sources used in commercial poultry feed (Sarwar Gilani et al. 2012). Studies have shown that increasing TI concentrations in soybean meal will lead to increased feed intake, decreased body weight gains, reduced feed efficiency, reduced protein digestibility, and predisposes the bird to subclinical NE (Mian and Garlich 1995; Palliyeguru et al. 2011; Hoffmann et al. 2019). Proper heat treatment is critical to ensure that TI has been destroyed (McNaughton et al. 1981). Although the industry has effectively learned how to properly process soybean meal, the opportunity to utilize raw beans and some poorly processed sources of full-fat soybeans do occur commercially, and as a result, TI does continue to pose a risk in the field. Moreover, emerging broiler rearing concepts such as organic husbandry mandates the utility of organic protein feedstuffs such as soybean meal to be processed without the use of solvents or chemical treatment (Leung and Kiarie 2020). As such available soybean meal for the organic broiler production is from mechanical oil extraction procedures which results in meals with markedly higher oil content and residual ANF (Woyengo et al. 2010; 2011; Kiarie et al. 2020).

\section{Phytic Acid}

Plant-based cereal grains are a source of phosphorus for poultry feed; however, the phosphorus contained within grains comes in the form of phytic acid. Phytic 
acid is poorly utilized by the animal and is known to bind and limit the availability of other nutrients contained within a diet (Woyengo and Nyachoti 2013). The antinutritional effects of phytic acid have been studied extensively throughout the years (Oatway et al. 2001; Singh 2008; Humer et al. 2015). The ingestion of phytic acid by broilers can influence amino acid and mineral availability as well as impacting lipid metabolism and deposition (Cowieson et al. 2003, 2004, 2006; Cowieson et al. 2008; Zaefarian et al. 2019). Overall performance is impacted by dietary levels of phytic acid as body weight gain and feed conversion ratio are compromised when birds consume increasing levels of phytic acid (Walk and Rama Rao 2020). Consequently, phytic acid is considered a potent ANF due to its ability to reduce broiler growth and overall performance (Cabahug et al. 1999; Woyengo and Nyachoti 2013).

\section{Tannins}

Tannins are water-soluble compounds that are capable of binding with other molecules (Leeson and Summers 2019). They are commonly found in low levels in faba beans, rapeseed, and canola meal. They are considered ANFs because of their ability to bind protein and reduce growth rate (Leeson and Summers 1997). Broiler chicks consuming tannins will exhibit reduced feed intake and growth rate which may partially be explained by a reduction of nitrogen retention. (Vohra et al. 1966). Vohra et al. (1966) also reported a high mortality rate when broiler chicks consumed tannic acid at $5 \%$ from days 7 to 11 .

\section{Mycotoxins}

Corn, corn by-products, wheat, and wheat by-products are all sources of mycotoxin contamination and need to be monitored closely due to their potential impact on broiler performance and gut health. The most common mycotoxins found in feed grains that are of interest to poultry production include aflatoxin produced by species of Aspergillus and deoxynivalenol, T-2 toxin produced by species of Fusarium. Although poultry consuming mycotoxins may not consistently show a reduction in overall growth performance, it is known that the mycotoxins are having a significant effect on intestinal morphology and organ weights (Awad et al. 2006; Awad et al. 2012; Ghareeb et al. 2015). It has been reported that feeds contaminated with mycotoxins will reduce performance, weight gain, and feed efficiency (Chi et al. 1977; Chowdhury and Smith 2004; Lee et al. 2017). Feeding mycotoxin-contaminated feed has also been shown to negatively impact gut morphology by decreasing the villus height and crypt depth in various sections of the small intestine (Awad et al. 2006; Antonissen et al. 2015). Conversely, other researchers have concluded that feeding broilers feed contaminated with mycotoxins did not adversely affect growth performance or feed intake (Sklan et al. 2001; Awad et al. 2006). The inconsistency in the effect of mycotoxin contamination on performance may be due to variations in the concentration of mycotoxins in the feed, length of exposure, and type of mycotoxin present (Awad et al. 2012). When birds are challenged with NE and mycotoxins are present in the feed, the use of antibiotics helps to improve weight gain resulting in an interaction between mycotoxin contamination and the use of antibiotics (Cravens et al. 2013). When birds are challenged with NE and fed high levels of mycotoxins in the absence of antibiotics, the negative effects associated with the disease including reduced weight gain, feed intake, and higher mortality are amplified (Cravens et al. 2015).

\section{Opportunities for Raising Birds Without Antibiotics}

For the last two decades, there has been tremendous investment on research and development of alternative feeding strategies and feed additives to bolster growth rate, organ weights, carcass yields, and feed efficiency in broiler chickens (Izat et al. 1989; Izat et al. 1991; Bedford 2000a; Awad et al. 2006; Gaucher et al. 2015; Wang et al. 2016; Wang et al. 2019a). The next section will highlight selective alternative feeding strategies that have been developed to support intestinal health and overall performance.

\section{Feed Processing}

The types of ingredients used in feed formulation and processing can play a significant role in improving or hindering performance (Kiarie et al. 2007; Kiarie and Mills 2019; Kiarie 2020). Modern commercial broiler feeds are manufactured by employing a combination of technologies including physical grinding with hammer and (or) roller mills in conjunction with hydrothermal processing such as pelleting, expansion, or extrusion (Schofield 2005; Goodarzi Boroojeni et al. 2016; Kiarie and Mills 2019). There are many benefits associated with feed processing including improved availability of nutrients, destruction of inhibitors and toxins, facilitation of the use of a wide range of raw materials in diet formulations, production of hygienic feed, and reduction of feed wastage (Schofield 2005; Abdollahi et al. 2013). For example, use of pelletized feed has created significant performance benefits resulting from improved quality, greater feed intake, and reduced bacterial contamination (Massuquetto et al. 2019). Pellet-fed birds showed improved feed efficiency, reduced intestinal $\mathrm{pH}$, reduced digesta viscosity, reduced $C$. perfringens and lactobacilli, and altered microbial fermentation when compared with mash-fed birds (Engberg et al. 2002). The performance benefits associated with pellet are linked with improved consistency of overall particle distribution, increased feed intake, and enhanced intestinal morphology as compared with birds fed mash feeds (Amerah et al. 2007). In addition, the heat treatment associated with the pelleting process will reduce some bacteria contained within the feed itself. Thereby 
reducing the bacterial load of the feed and the opportunity for feed to serve as a source of bacterial contamination (Haberecht et al. 2020).

Although pelleting feed has become a standard process in the production of commercial feed, there are numerous studies that have shown that birds fed a pelleted diet had significantly decreased gizzard development linked to the lack of stronger mechanical stimulation (Nir et al. 1995; Dahlke et al. 2003; Huang et al. 2006; Amerah et al. 2007; Rezaeipour and Gazani 2014; Röhe et al. 2014). The peculiarity is that the hydrothermal processing employed during pelleting further reduces feed particle size as exemplified by minimization of the differences in the particle size distribution of coarse and medium grindings (Abdollahi et al. 2016). During pelleting process, the feed is passed through steam, which softens the feed particles before they are pressed through the die by the rolls in the pellet press, causing an additional grinding effect. As a consequence, studies reported decreased gizzard and pancreas weights in birds fed pelleted feed compared with mash feed linked to particle size reduction (Goodarzi Boroojeni et al. 2016). It is thought that weaker mechanical stimulation by the feed might explain the higher $\mathrm{pH}$ found in the gizzards of pellet-fed birds due to a decrease in $\mathrm{HCl}$ secretion than in mash-fed chicks (Huang et al. 2006). Reduction of proventriculus/gizzard function has been linked to poor gastrointestinal health and function (Svihus 2011). For example, birds fed pelleted diets had significantly higher concentrations of Salmonella enterica serovar Typhimurium DT12 in the GIT than birds fed mash (Huang et al. 2006). Bjerrum et al. (2005) reported that birds fed pelleted feed had higher numbers of Salmonella in gizzards compared with those given whole wheat. Interestingly, pelleted diets have been shown to increase concentrations of SCFA in the gizzard compared with mash feeds. The increased SCFA in gizzard was not accompanied with lower $\mathrm{pH}$ in gizzard of birds fed pelleted diet (Huang et al. 2006). However, feeding pelleted diets increased ceca concentration of SCFA which was accompanied with decreased $\mathrm{pH}$ (Engberg et al. 2002; Huang et al. 2006). This was explained to be related to the fact that pelleting induced a substantial reduction in particle size such that nutrients that entered the cecum were easily available for microbial fermentation. There are few studies investigating the effects of pelleting on gastrointestinal microbiology in broilers; however, a better understanding of the effects of steam conditioning time and temperature manipulations could help the producers maintain hygienic, physical, and nutritional quality of feed in an antibiotic-free feeding programs.

The process of fermenting feeds or specific ingredients has been investigated as a feeding strategy for monogastric species (Song et al. 2010; Missotten et al. 2013; Sugiharto and Ranjitkar 2019; Yan et al. 2019). For poultry, ingredients such as fermented or pre-treated soybean meal have gained attention due to the presence of antibacterial compounds created as a result of the fermentation process (Jazi et al. 2018; Jazi et al. 2019). In addition to the presence of antibacterial compounds, the fermentation process results in the production of small peptides, reduced ANF, and enhanced digestibility. These beneficial compounds paired with enhanced digestibility have resulted in improved performance as well as improved intestinal morphology and balanced microbial diversity (Feng et al. 2007; Jazi et al. 2018) The limiting factor in commercial application is the cost associated with the fermented products (Wang et al. 2012).

\section{Utility of Exogenous Feed Enzymes}

Feedstuffs contain ANF such as phytic acid or fractions that are not degraded sufficiently or indeed at all by the conditions and the array of digestive enzymes in the GIT (Kiarie et al. 2013; Kiarie et al. 2016). This inherent digestive inefficiency in monogastric animals is seen as the reason of commercial development and application of exogenous feed enzymes technology. Indigestible complexes can impede normal digestion and absorption processes of nutrients including carbohydrates and protein (Slominski 2011). The broiler chicken does not possess the ability to break down phytic acid, and as a result, the use of exogenous phytase enzymes has been developed to hydrolyze phytic acid and reduce the negative effects associated with this ANF (Abd El-Hack et al. 2018). Results have shown that when broilers consume phytic acid without the use of exogenous phytase, almost all of the phytate can be recovered in the excreta (Cowieson et al. 2004). The addition of exogenous phytase to diets has been shown to result in improved performance in broilers consuming increasing levels of phytic acid (Walk and Rama Rao 2020). This may be due to the ability of exogenous phytase to liberate phytatebound nutrients such as phosphorus and amino acid (Ravindran et al. 2006).

The negative effects from NSP can be overcome with the addition of enzymes such as xylanase, $\beta$-glucanase, $\beta$-mannanase, $\alpha$-galactosidase, and pectinase (Brenes et al. 1993; Bedford 2000b; Kiarie et al. 2013; Munyaka et al. 2016). Exogenous enzymes are added to feed to help improve the foregut digestibility so that less substrate is passed to the ileum and ceca and used as a food source for the pathogenic bacteria residing in the hindgut. Exogenous enzymes have been found to improve performance when added to both corn- and wheat-based diets (Kiarie et al. 2007; Kiarie et al. 2014; Yan et al. 2017; Park and Kim 2018; Sanchez et al. 2019) making them very attractive in commercial feed formulation. The addition of exogenous enzymes to broiler diets is linked to changing the digestibility of ingredients which can then alter the ileal and cecal microbial population (Choct et al. 1999; Liu and Kim 2016; Munyaka et al. 2016; Kiarie et al. 2019; Kiarie 2020). Increasing digestibility of poorer 
quality ingredients while reducing undigested nutrients from making their way to the hindgut is essential for birds fed with and without the use of AGP. It has been suggested that the application of exogenous enzymes may reduce endogenous losses of nutrients thereby reducing their availability as substrates for the bacterial community. By limiting nutrient availability in the hindgut, it is possible that exogenous enzymes are indirectly modulating the bacterial community (Bedford 2000a; Kiarie et al. 2013). Consequently, the additions of exogenous enzymes to feed have become a necessary tool for any modern poultry feeding program.

\section{Utility of Gastrointestinal Ecology Modulators}

As we move away from the use of antibiotics in feed, we need to be prepared to use alternative strategies to inhibit and control the population of Clostridium in the small intestine of poultry. Campylobacter and Salmonella are considered pathogenic bacteria that reside in the chicken microbiome that do not necessarily harm the host but are a risk to human health. Consequently, there has been a focus on controlling/maintaining these bacteria at low levels so that we reduce the incidence of foodborne illness in humans consuming poultry products. Due to the influence of the microbiome on overall health and bird performance, many researchers have focused on feed additives to manipulate or maintain stability of the microbiome so that harmful and pathogenic bacterial like E. coli, Clostridium, Salmonella, and Camplyobacter do not thrive at the expense of beneficial bacterial such as Lactobacillus. The use of alternative ingredients in poultry diets has become a common strategy to maintain gut health and performance when we reduce or remove antibiotics. Many products have been reported to have a growth-promoting effect and consequently, have been a focus for the feed industry as an alternative to antibiotics. However, the growthpromoting effects of antibiotic alternatives are extremely variable, and efficacy may be dependent on the type of diet, environment, and management within the barn (Yang et al. 2009; Houshmand et al. 2011).

\section{Probiotics}

Probiotics or direct-fed microbials are one of the main ingredient types that have been studied as a result of their impact on broiler performance and immune response (Waititu et al. 2014; Kridtayopas et al. 2019). Probiotics are live cultures of microorganisms that benefit the animal by populating the microbiome with harmless bacteria that compete for the same resources, obstruct attachment sites, and produce metabolites such as volatile fatty acids that can limit the proliferation of pathogenic bacteria, stimulate immune function, and improve feed intake and digestion (Patterson and Burkholder 2003; Ajuwon 2016). The growth promotion and feed efficiency effect of probiotics in chickens has been well documented (Awad et al. 2009; Mountzouris et al. 2010; Molnar et al. 2011; Cao et al. 2013). Adding a probiotic to feed and water showed a growth-promoting effect in broilers up to $6 \mathrm{wk}$ of age (Mountzouris et al. 2007). Feeding probiotics has also been proven to reduce cecal E. coli and reduce cecal coliforms in broiler chickens (Jin et al. 1998; Mountzouris et al. 2007; Wang et al. 2017). Reduced mortality has been reported as the result of bacterial infection when chickens were fed Bacillus subtillus probiotic (Harrington et al. 2016). The effectiveness of a probiotic to elicit a performance or immune response may be dependent on the strain of bacteria used in culture, the combination of different strains, the number of colony-forming units supplied in the feed, the timing and frequency of application, the age of the bird, stress, and diet composition (Mountzouris et al. 2010; Mikulski et al. 2012; Yun et al. 2017). Hutsko et al. (2016) reported that although two Bacillus-based probiotics were fed to turkey poults, the resulting effect on villus and crypt development was not the same. An increase in villus height : crypt depth ratio as a result of feeding probiotics is linked to improved growth performance in broilers (Awad et al. 2009). It has been stated that the efficacy of a probiotic is dependent on the species ability to survive and colonize the gut to fully capitalize on the beneficial functions performed by these species (Jin et al. 1998). The efficacy of probiotics relating to growth performance responses in broiler chickens is summarized in Table 4.

\section{Prebiotics}

Prebiotics are non-digestible carbohydrates such as mannanoligosaccharides and fructooligosaccharides that can influence the diversity of the microbial population as a result of selectively influencing the harmless or beneficial bacteria at the expense of pathogenic bacteria. Prebiotics added to the diet of broiler chicks enhanced the population of Lactobacillus and Bifidobacterium while inhibiting or maintaining E. coli populations at a lower level in the small intestine and cecal digesta (Xu et al. 2003). The addition of a prebiotic, therefore, favors a balanced microbiome which then leads to good performance (Kogut 2017). There have been conflicting reports regarding the performance benefits associated with feeding prebiotics. Although some researchers have reported an increase in growth performance and feed efficiency as a result of incorporating prebiotics into the diet (Xu et al. 2003; Kridtayopas et al. 2019), others have been unsuccessful in reporting a similar growth response (Baurhoo et al. 2009; Houshmand et al. 2012). The lack of a performance response when birds are fed prebiotics may be due to the sanitary conditions under which the birds are raised. The true benefits of feeding prebiotics may only be expressed when birds are reared in commercial farms where a microbial challenge is present (Houshmand et al. 2012).

Synbiotics are defined as the combination of probiotics and prebiotics together (Yang et al. 2009). There have 
Table 4. Performance response of in-feed probiotics relative to a negative control.

\begin{tabular}{|c|c|c|c|c|}
\hline Species & $\begin{array}{l}\text { Concentration in } \\
\text { feed }\end{array}$ & Diet composition & $\begin{array}{l}\text { Performance } \\
\text { response }\end{array}$ & Reference \\
\hline $\begin{array}{l}\text { Bacillus subtillis } \\
\text { (DSM17229) }\end{array}$ & $8 \times 10^{8} \mathrm{cfu} \cdot \mathrm{kg}^{-1}$ & Corn, soy, meat meal & $\begin{array}{l}\text { Increased BWG, } \\
\text { improved FCR }\end{array}$ & Harrington et al. 2016 \\
\hline Bacillus subtillis (29784) & $1 \times 10^{8} \mathrm{cfu} \cdot \mathrm{kg}^{-1}$ & Corn, soy & $\begin{array}{l}\text { Increased BWG, } \\
\text { improved FCR }\end{array}$ & Jacquier et al. 2019 \\
\hline Bacillus subtillis (PB6) & $2.7 \times 10^{8} \mathrm{cfu} \cdot \mathrm{kg}^{-1}$ & Corn, soy & $\begin{array}{l}\text { Increased BWG, } \\
\text { improved FCR }\end{array}$ & Jayaraman et al. 2017 \\
\hline $\begin{array}{l}\text { Bacillus subtillis (strain } \\
\text { not specified) }\end{array}$ & $2 \times 10^{12} \mathrm{cfu} \cdot \mathrm{kg}^{-1}$ & $\begin{array}{l}\text { Corn, soy, sunflower } \\
\text { cake }\end{array}$ & Improved FCR & Ramlucken et al. 2020 \\
\hline $\begin{array}{l}\text { Bacillus subtillis (three } \\
\text { strains not specified) }\end{array}$ & $7.5 \times 10^{7} \mathrm{cfu} \cdot \mathrm{kg}^{-1}$ & $\begin{array}{l}\text { Wheat, barley, rye, } \\
\text { soy }\end{array}$ & $\begin{array}{l}\text { No response on } \\
\text { BWG, FCR }\end{array}$ & Waititu et al. 2014 \\
\hline $\begin{array}{l}\text { Propionibacterium } \\
\text { acidipropionici }\end{array}$ & $7.5 \times 10^{7} \mathrm{cfu} \cdot \mathrm{kg}^{-1}$ & - & $\begin{array}{l}\text { No response on } \\
\text { BWG, increased } \\
\text { FCR }\end{array}$ & \\
\hline $\begin{array}{l}\text { Five-strain product: } \\
\text { Lactobacillus reuteri } \\
\text { (DSM16350), } \\
\text { Enterococcus faecium } \\
\text { (DSM16211), } \\
\text { Bifidobacterium } \\
\text { animalis (DSM16284), } \\
\text { Pediococcus acidilactici } \\
\text { (DSM1621), } \\
\text { Lactobacillus salivarius } \\
\text { (DSM16351) }\end{array}$ & $\begin{array}{l}1 \times 10^{8} \mathrm{cfu} \cdot \mathrm{kg}^{-1} \\
1 \times 10^{9} \mathrm{cfu} \cdot \mathrm{kg}^{-1} \\
1 \times 10^{10} \mathrm{cfu} \cdot \mathrm{kg}^{-1}\end{array}$ & $\begin{array}{l}\text { Corn, soy } \\
- \\
- \\
-\end{array}$ & $\begin{array}{l}\text { Increased BWG, } \\
\text { improved FCR } \\
\text { No response on } \\
\text { BWG or FCR } \\
\text { No response on } \\
\text { BWG or FCR }\end{array}$ & Mountzouris et al. 2010 \\
\hline
\end{tabular}

Note: cfu, colony-forming units; BWG, body weight gain; FCR, feed conversion ratio; DDGS, corn distillers' dried grains with solubles.

been several papers published on the performance benefits of feeding a combination of probiotics and prebiotics together (Awad et al. 2009; Wang et al. 2016; Wang et al. 2019b). While other studies have reported that prebiotics and probiotics have no impact on improving broiler growth (Houshmand et al. 2011; Wang et al. 2019a). Ajuwon (2016) reported that the inconsistent effect of probiotics and prebiotics is related to the species used in the product, timing of application, stress, environment, and antibiotic use. It has been suggested that more research is required in these areas (Abdelrahman et al. 2014).

\section{Phytogenic Feed Additives}

Phytogenic feed additives are a class of feed ingredients consisting of botanical components such as herbs, spices, and essential oils. These types of additives have been researched due to their performanceenhancing effects as well as their antimicrobial properties (Diaz-Sanchez et al. 2015; Santi Devi 2017). Birds fed essential oils have resulted in heavier body weights (Khattak et al. 2013), increased feed digestibility (Hernández et al. 2004), increased breast meat yield (Khattak et al. 2013), and increased feed intake and enzyme activity (Hashemipour et al. 2013). However, the response of broilers to phytogenic feed additives may differ depending on the type and combination of additive (Cross et al. 2007; Mohiti-Asli and Ghanaatparast-Rashti 2017), dose (Oso et al. 2019), ingredients used in formulation, and environmental conditions (Lee et al. 2003). Data shows variable application rates regarding the dose of phytogenic feed additives 
Table 5. Performance response of common phytogenic feed additives used in poultry feed.

\begin{tabular}{|c|c|c|}
\hline Phytogenic blend & Performance response & Reference \\
\hline Aerva lanata & Decreased mortality & \multirow[t]{4}{*}{ Oso et al. 2019} \\
\hline Piper betle & Increased growth & \\
\hline Cynodon dactylon & Increased intestinal morphology & \\
\hline Piper nigrum & & \\
\hline Thymol & Improved body weight gain & \multirow[t]{2}{*}{ Hashemipour et al. 2013; Du et al. 2016} \\
\hline Carvacrol & $\begin{array}{l}\text { Enhanced enzyme activity } \\
\text { Improved immune response } \\
\text { Decreased lipid oxidation } \\
\text { Reduced inflammatory response }\end{array}$ & \\
\hline Oregano & Increased goblet cells and enhanced pathogen & \multirow[t]{3}{*}{ Reisinger et al. 2011} \\
\hline Anise & Barrier & \\
\hline Citrus peel & & \\
\hline Basil & \multirow[t]{8}{*}{ Increased body weight gain } & \multirow[t]{8}{*}{ Khattak et al. 2013} \\
\hline Caraway & & \\
\hline Laurel & & \\
\hline Lemon & & \\
\hline Oregano & & \\
\hline Sage & & \\
\hline Tea & & \\
\hline Thyme & & \\
\hline Thymol & No performance benefits & Lee et al. 2003 \\
\hline Cinnamaldehyde & & \\
\hline Thymol & Increased growth performance & \multirow[t]{2}{*}{ Mohammadi Gheisar et al. 2015} \\
\hline Vanillin & $\begin{array}{l}\text { Decreased drip loss } \\
\text { Increased fecal Lactobaciullus }\end{array}$ & \\
\hline Oregano oil & $\begin{array}{l}\text { No performance benefit } \\
\text { Antioxidant effect }\end{array}$ & Botsoglou et al. 2002 \\
\hline Thymol & $\begin{array}{l}\text { No performance benefit } \\
\text { Increased digestive enzyme activity }\end{array}$ & Jang et al. 2007; Haselmeyer et al. 2015 \\
\hline $\begin{array}{l}\text { Thyme } \\
\text { Oregano } \\
\text { Marjoram } \\
\text { Rosemary } \\
\text { Yarrow }\end{array}$ & Individual herbs evaluated with variable response & Cross et al. 2007 \\
\hline
\end{tabular}

and concerns have been raised regarding possible toxicity as well as compromised performance when doses are too high (Timbermont et al. 2010). This category of feed additives includes a wide variety of active ingredients with a limited understanding of their mode of action. A summary of common phytogenic feed additives used in poultry feed and growth performance responses is summarized in Table 5.

\section{Organic Acids}

Organic acids are a group of chemicals commonly referred to as fatty acids, volatile fatty acids, or carboxylic acid with the general structure $\mathrm{R}-\mathrm{COOH}$ (Dibner and Buttin 2002; Ricke 2003). Some common organic acids include formic acid, acetic acid, propionic acid, butyric acid, lactic acid, sorbic acid, fumaric acid, 2-hydroxy-4-(methylthio) butanoic acid, malic acid, tartaric acid, and citric acid (Dibner and Buttin 2002). The addition of organic acids to broiler feed has been shown to increase weight gain and improve feed efficiency
(Patten and Waldroup 1988; Skinner et al. 1991; Leeson et al. 2005; Adil et al. 2010; Kaczmarek et al. 2016). The performance benefits associated with feeding organic acids to poultry have been hypothesized to be the result of increased enzyme activity, enhanced amino acid digestibility, altered $\mathrm{pH}$, and adjustments to the microbiome (Patten and Waldroup 1988; Moquet et al. 2018). Organic acids reduce upper gut $\mathrm{pH}$ thereby making the environment inhabitable by acid-intolerant bacteria. Bourassa et al. (2018) found that adding formic acid to feed or water decreased Salmonella in the ceca. The addition of organic acids to feed has been shown to reduce E. coli (Emami et al. 2017). The combination of organic acids and medium-chain fatty acids has been shown to increase Lactobacillus populations and decrease E. coli populations in excreta (Nguyen et al. 2018). Feeding butyric acid to broilers was shown to alter the cecal colonization of Salmonella (Van Immerseel et al. 2005). Commercially, butyric acid is available in the form of butyrate (calcium or sodium salt). The metabolism of butyrate products 
Table 6. Strategies used in commercial broiler diets in the absence of antibiotic growth promotors.

\begin{tabular}{|c|c|c|}
\hline Feed strategy & Example & Reference \\
\hline \multirow[t]{4}{*}{ Maximize nutrient digestibility } & High quality ingredients & Loar et al. 2010; Cervantes 2015 \\
\hline & Limited wheat/barley/rye & $\begin{array}{l}\text { MacAuliffe and McGinnis 1971; } \\
\text { Annett et al. 2002; Tellez et al. } \\
\text { 2014; Broom } 2017\end{array}$ \\
\hline & Enzyme application & $\begin{array}{l}\text { Brenes et al. 1993; Bedford 2000a; } \\
\text { Kiarie et al. 2014; Munyaka et al. } \\
2016\end{array}$ \\
\hline & Phytogenic feed additives & $\begin{array}{l}\text { Hernández et al. 2004; Diaz- } \\
\quad \text { Sanchez et al. 2015; Oso et al. } 2019\end{array}$ \\
\hline \multirow[t]{7}{*}{ Manage gut microbiome } & High quality ingredients & $\begin{array}{l}\text { Perez et al. 2011; Cervantes 2015; } \\
\text { Shang et al. } 2020\end{array}$ \\
\hline & All vegetable diet & $\begin{array}{l}\text { Wilkie et al. 2005; Wise and } \\
\text { Siragusa 2007; Zanu et al. } 2020\end{array}$ \\
\hline & Limited mycotoxin exposure & $\begin{array}{l}\text { Cravens et al. 2013; Antonissen } \\
\text { et al. 2015; Cravens et al. } 2015\end{array}$ \\
\hline & Probiotics/prebiotics & $\begin{array}{l}\text { Patterson and Burkholder 2003; Xu } \\
\text { et al. 2003; Baurhoo et al. 2009; } \\
\text { Abdelrahman et al. 2014; } \\
\text { Mohammadigheisar et al. } 2020\end{array}$ \\
\hline & Betaine & $\begin{array}{l}\text { Kettunen et al. 2001; Amerah and } \\
\text { Ravindran } 2015\end{array}$ \\
\hline & Phytogenic and phenolic compounds & $\begin{array}{l}\text { Diaz-Sanchez et al. 2015; Park and } \\
\text { Kim 2018; Das et al. } 2020\end{array}$ \\
\hline & Organic acids & $\begin{array}{l}\text { Emami et al. 2017; Bourassa et al. } \\
\text { 2018; Nguyen et al. } 2018\end{array}$ \\
\hline Improved immunity & Vaccine & Chapman 2014; Ritzi et al. 2016 \\
\hline
\end{tabular}

will begin at the crop and continue through the upper GIT thereby limiting the amount of butyrate that makes it to the lower intestine (Kaczmarek et al. 2016). Unprotected butyrate will exhibit its effects on the epithelial cells of the crop, proventriculus, and gizzard (Moquet et al. 2016). New technologies have become available whereby the sodium or calcium salts are coated or encapsulated by plant-based triglycerides such as hydrogenated palm oil (Kaczmarek et al. 2016; Liu et al. 2019). Encapsulation ensures that the butyrate can bypass the upper GIT and reach the lower intestinal tract where it can exhibit the greatest efficacy (Leeson et al. 2005; Van Immerseel et al. 2005; Liu et al. 2017). Due to their antimicrobial properties, organic acids are able to modify the microbial community in the intestine (Broom 2015; Kiarie et al. 2016; Kiarie et al. 2018). This may lead to a reduction in the number of pathogens that the mucous layer must defend itself from, allowing intestinal barrier function to be maintained.

\section{Betaine}

Glycine betaine or betaine is the trimethyl derivative of the amino acid glycine. It is well known for its osmoregulant properties and as a methyl group donor resulting in many studies investigating its impact on broilers challenged with coccidiosis (Augustine et al. 1997; Matthews and Southern 2000; Klasing et al. 2002;
Metzler-Zebeli et al. 2009; Amerah and Ravindran 2015). Researchers have hypothesized that betaine can protect the lining of the small intestine and thereby exhibit a protective effect in the face of a coccidial challenge as a result of maintaining villus integrity and structure (Kettunen et al. 2001; Metzler-Zebeli et al. 2009). The addition of betaine to broiler feed has also been shown to have an influence on intestinal morphology by decreasing crypt:villus ratio (Kettunen et al. 2001). Research studying the impact of dietary betaine on birds challenged with coccidiosis reports that the efficacy of some coccidiostats may be improved when used in combination with betaine supplementation (Augustine et al. 1997). It is thought that the protective effects of betaine during a coccidiosis challenge are due to its osmoregulant properties whereby betaine accumulates in the intestinal cells and may offset the osmotic stress produced by diarrhea and dehydration caused by the invasion of coccidiosis (Fetterer et al. 2003).

\section{Cocktail Blends}

Cocktail-like additives that include a combination of organic acids, oligosaccharides, and plant extracts are effective in influencing the microbiome as they have been shown to reduce cecal E. coli and Salmonella counts (Manafi et al. 2019). Askelson et al. (2018) used an in-feed probiotic-enzyme blend to manipulate the chicken 
microbiome and increase lactic acid bacteria while reducing Clostridium. Improvements in body weight gain and feed conversion ratio have also been reported in birds fed probiotic-enzyme blends (Wealleans et al. 2017). The effectiveness of cocktail blends depends on their synergistic effect to improve performance in the absence of AGP. Products with different modes of action may work together to improve the stability of the microbiome. However, the efficacy of such products may depend on their specific combination of additives as not all combinations will be effective in producing a response (Wang et al. 2016).

\section{Challenges of Application of Research Data in Commercial Production Environments}

It is possible to raise broilers without the use of AGP, but the removal of antibiotics is associated with a reduction in performance (Gaucher et al. 2015). The lost performance combined with the higher feed cost associated with the removal of AGP makes RWA production far less sustainable than conventional broiler production (Cervantes 2015). Yet, these programs are currently utilized across Canada to meet a consumer demand for chicken that has been marketed as a healthier choice. Although research on alternatives to antibiotics is ongoing, nothing has been identified that matches the efficacy of antibiotics (Smith 2011). A single feed ingredient has yet to be employed as a full replacement to antibiotics for the prevention of NE and (or) growth promotion (Dibner and Buttin 2002; Smith 2011). Therefore, it is critical to apply a multifactorial approach which includes elevated management strategies, vaccination programs, and a robust feeding strategy. Table 6 summarizes strategies currently used in the production of commercial broilers raised without the use of antibiotics. An ideal feeding program uses consistent feed ingredients that support gastrointestinal health and function to maximize digestion and absorption of nutrients while minimizing the excretion of nutrients. The end goal is the same regardless of the production system: to maintain good gut health while meeting performance and welfare objectives.

An inability to produce a positive and consistent responses from antibiotic alternatives has been reported in studies done in research settings (Ajuwon 2016). The notion held by the industry and regulators is that if a product shows efficacy in research conditions, then it should work in a commercial farm setting. The limiting factor in such clean settings is the lack of exposure to exogenous bacteria and environmental stress that commercial birds would experience (Wang et al. 2016). It has been stated that healthy chicks on a highly digestible diet will fail to respond to dietary additives when reared under sanitary conditions (Lee et al. 2003). As a result, the response of birds to AGP alternatives raised under commercial farm settings remains unclear. Studies done in a research setting may be too clean to truly evaluate the effect of alternative ingredients (Apajalahti et al. 2004; Kiarie et al. 2007; Baurhoo et al. 2009). In this context, some researchers have suggested such evaluations be conducted under a commercial setting (Milbradt et al. 2014). It is important to evaluate the true impact of alternative (antibiotic-free or reduced antibiotic) feeding programs on the overall health of commercial broilers because differences in research and commercial settings may be influencing the overall response of birds to such programs and the alternatives contained within them. Consequently, data from university or institute settings may not be predictive of how these solutions work in commercial situations. Moreover, research and development of alternative solutions such as feed additives rarely takes the view that broilers in commercial production receive diets with a range of distinct additives.

\section{Variations Between Research at University and Commercial Settings}

Different stresses commonly experienced by birds living in commercial settings have been researched as triggers for intestinal damage. These include heat stress, stocking density, and extended periods of feed withdrawal (Zhang et al. 2017; He et al. 2018; Goo et al. 2019). Chronic heat stress has been shown to decrease feed intake and overall growth performance which is correlated to damaged intestinal morphology and compromised barrier function (He et al. 2018). Stocking density relates to the number of birds or the number of kilograms living in a defined amount of floor space. The maximum stocking density for broiler chickens in Canada is $31 \mathrm{~kg} \cdot \mathrm{m}^{-2}$ of floor space (National Farm Animal Care Council 2016). As stocking density increases the ability of the birds' intestine to act as a barrier against pathogens is decreased (Goo et al. 2019). It has been hypothesized that the stress response decreases blood flow to the GIT leading to epithelial cell damage and malfunctioning tight junctions (Lambert 2009). Extended periods of feed withdrawal have also been highlighted as a trigger for impaired intestinal barrier function (Zhang et al. 2016). These types of stresses are not likely to be experienced in a tightly regulated research setting where all aspects of the environment are controlled but are likely to be experienced by birds reared under commercial conditions.

Water quality is another important factor that should be considered in commercial settings. Canadian poultry producers will have access to water from various sources such as municipal, deep well, pond, rainwater, or combined sources stored in a cistern, and filterd or sanitized to varying degrees or not at all. Studies have reported that differing water sources and storage methods can contribute to altered water quality (Elsaidy et al. 2015). Water can be a source of bacteria which may transmit enteric pathogens directly to livestock (Kemp et al. 2005; Doyle and Erickson 2006). Contamination of the environment is inevitable due to exposure to wild birds, 
wild animals, agricultural run-off, and sewage effluent (Jones 2001). As a result, deep well, pond, or lake water may be especially vulnerable to bacterial contamination compared with tap water. Mineral content of water is also influenced by the source. Deep well water is more likely to have higher levels of mineral contaminants compared with municipal sources which can contribute to flushing and wet litter (Koelkebeck et al. 1999). The bacterial and mineral content of water is critically important and should be monitored regularly as they can impact overall performance (Barton 1996). Birds reared in academic research settings may not experience the same variation or potential quality issues as birds reared in commercial settings. Published research does not typically report water source.

Commercial feed mills formulate poultry diets based on ingredient availability, price, and quality. The stability of these parameters can be somewhat uncertain due to the fluctuations in the open markets. To accommodate such fluctuations, feed mills may alter their formulations every 7-10 d (Pathumnakul et al. 2011). Consequently, birds reared under commercial conditions can experience many changes in their diet composition that are the result of unstable commodity markets and ingredient availability. This can contribute to some inconsistency in feed from batch to batch. These rapidly changing diets are not experienced by birds in research settings as they are often fed a test diet for a specified period. These rapid swings in dietary composition experienced by birds reared in commercial settings may contribute to the onset of enteric diseases as diets may suddenly include less digestible ingredients, higher levels of NSP, varying levels of animal proteins or expose birds to higher levels of mycotoxins.

Due to the sanitary conditions associated with research settings, it has become common to stimulate a bacterial or coccidiosis infection by creating a challenge model whereby birds are exposed to high numbers of coccidial oocysts or bacteria using an oral gavage. To stimulate this type of coccidiosis challenge, birds will receive an amplified dose of a coccidiosis vaccine containing live oocyts from Eimeria species (E. maxima, E. tenella, and E. acervulina) (Kiarie et al. 2019; Leung et al. 2019; Wang et al. 2019b). To simulate a bacterial challenge, birds can receive an inoculum of $C$. perfringens or E. coli via oral gavage (Emami et al. 2017; Belote et al. 2018). These types of challenge models may be limiting in their ability to produce consistent and reproducible results (Pedersen et al. 2003; Shojadoost et al. 2012). It has been suggested that it is difficult to produce enteric diseases in research conditions due to inadequate knowledge of other predisposing factors (Pedersen et al. 2008). As a result, it is very difficult to reproduce field conditions in a research setting. It can be argued that the work done in research settings to investigate feeding strategies associated with antimicrobial reduction also need to be evaluated in commercial settings whereby the true field challenges associated with commercial production can be employed as predisposing factors known to trigger enteric diseases. There is interest in evaluating bird performance and overall health under commercial farm conditions. This has been supported in academia through the publication of some studies done in commercial settings (Diarrassouba et al. 2007; Bray et al. 2009; Gaucher et al. 2015; Parent et al. 2020).

\section{Summary and Future Perspectives}

The poultry industry is tasked with developing feed programs that maintain optimal gut health while meeting performance and welfare objectives under the challenging environments experienced by birds in a commercial operation. Research has proven that feeding programs, specific ANF, and ingredients are influencing overall growth rate and feed efficiency while having a strong effect on the diversity of the microbiota. Antibiotics are proven to produce relatively consistent performance results while preventing enteric diseases. However, alternative ingredients such as probiotics, prebiotics, essential oils, and organic acids designed to replace antibiotics are not producing results with the same degree of consistency. Furthermore, these dietary concepts have been investigated as stand-alone strategy and are being applied within the poultry industry to support broiler markets with varying use of antibiotic applications. The application of these concepts as part of a commercial broiler feed program has not been evaluated throughout the life of a flock. There is a gap in the research regarding the combination of commodity ingredients and feed additives that could be used synergistically in feeding programs to support the bird without the reliance on antibiotics. Highly controlled research settings may be limiting the beneficial effects of antibiotic alternatives and consequently, there are gaps regarding the efficacy of such ingredients under more realistic commercial conditions. From a research perspective, there is a lack of comparative data on indices on growth, meat yield, blood biochemistry, body composition, and gut morphology of birds raised on conventional and alternative feed programs in commercial farms. The consumer demand for meat-protein produced without the reliance on antibiotics will continue to pressure the industry to further reduce and eliminate more classes of antibiotics. As a result, the poultry industry needs to have a clear understanding of how to develop feeding programs that use a synergistic application of alternative ingredients in realistic diets and commercial farms to facilitate the successful replacement of AGP. By focusing on programs that maximize digestibility and manage the microbiota while supporting immunity, the removal of AGP should not have a negative impact on bird health parameters, physiology, performance or increase the occurrence of enteric diseases. 


\section{Author Contributions and Conflict of Interests}

LBH is a graduate student of EGK, she searched literature and wrote significant portion of the review. EGK overall conceptual and editorial responsibility. The authors declare that the research was conducted in the absence of any commercial or financial relationships that could be construed as a potential conflict of interest.

\section{Acknowledgements}

Ontario Agri-Food Innovation Alliance and Natural Sciences and Engineering Research Council of CanadaDiscovery Program for provision of base funding of EGK gut health research program. Appreciation to the support of New-Life Mills to $\mathrm{LBH}$ graduate studies at University of Guelph. Contributions of the current and former graduate students and research associates of EGK Monogastric Nutrition Research Laboratory at University of Guelph appreciated.

\section{References}

Abd El-Hack, M.E., Alagawany, M., Arif, M., Emam, M., Saeed, M., Arain, M.A., et al. 2018. The uses of microbial phytase as a feed additive in poultry nutrition - a review. Ann. Anim. Sci. 18: 639-658. doi:10.2478/aoas-2018-0009.

Abdelrahman, W., Mohnl, M., Teichmann, K., Doupovec, B., Schatzmayr, G., Lumpkins, B., and Mathis, G. 2014. Comparative evaluation of probiotic and salinomycin effects on performance and coccidiosis control in broiler chickens. Poult. Sci. 93: 3002-3008. doi:10.3382/ps.2014-04212. PMID:25332136.

Abdollahi, M.R., Ravindran, V., and Svihus, B. 2013. Pelleting of broiler diets: an overview with emphasis on pellet quality and nutritional value. Anim. Feed Sci. Technol. 179: 1-23. doi:10.1016/j.anifeedsci.2012.10.011.

Abdollahi, M.R., Ravindran, V., and Amerah, A.M. 2016. Influence of partial replacement of ground wheat with whole wheat and exogenous enzyme supplementation on growth performance, nutrient digestibility and energy utilization in young broilers. J. Anim. Physiol. Anim. Nutr. (Berl.) 100: 929-937. doi:10.1111/jpn.12472. PMID:27080922.

Adil, S., Banday, T., Bhat, G.A., Mir, M.S., and Rehman, M. 2010. Effect of dietary supplementation of organic acids on performance, intestinal histomorphology, and serum biochemistry of broiler chicken. Vet. Med. Int. 2010: 479485. doi:10.4061/ 2010/479485. PMID:20613998.

Afsharmanesh, M., Sadaghi, B., and Silversides, F.G. 2013. Influence of supplementation of prebiotic, probiotic, and antibiotic to wet-fed wheat-based diets on growth, ileal nutrient digestibility, blood parameters, and gastrointestinal characteristics of broiler chickens. Comp. Clin. Pathol. 22: 245-251. doi:10.1007/s00580-011-1393-2.

Agyekum, A.K., Slominski, B.A., and Nyachoti, C.M. 2012. Organ weight, intestinal morphology, and fasting whole-body oxygen consumption in growing pigs fed diets containing distillers dried grains with solubles alone or in combination with a multienzyme supplement. J. Anim. Sci. 90: 3032-3040. doi:10.2527/jas.2011-4380. PMID:22966079.

Ajuwon, K.M. 2016. Toward a better understanding of mechanisms of probiotics and prebiotics action in poultry species. J. Appl. Poult. Res. 25: 277-283. doi:10.3382/japr/pfv074.

Allaart, J.G., van Asten, A.J., and Grone, A. 2013. Predisposing factors and prevention of Clostridium perfringens-associated enteritis. Comp. Immunol. Microbiol. Infect. Dis. 36: 449-464. doi:10.1016/j.cimid.2013.05.001. PMID:23790636.
Amerah, A.M., and Ravindran, V. 2015. Effect of coccidia challenge and natural betaine supplementation on performance, nutrient utilization, and intestinal lesion scores of broiler chickens fed suboptimal level of dietary methionine. Poult. Sci. 94: 673-680. doi:10.3382/ps/pev022. PMID:25691757.

Amerah, A.M., Ravindran, V., Lentle, R.G., and Thomas, D.G. 2007. Influence of feed particle size and feed form on the performance, energy utilization, digestive tract development, and digesta parameters of broiler starters. Poult. Sci. 86: 2615-2623. doi:10.3382/ps.2007-00212. PMID:18029808.

Amit-Romach, E., Sklan, D., and Uni, Z. 2004. Microflora ecology of the chicken intestine using 16S ribosomal DNA primers. Poult. Sci. 83: 1093-1098. doi:10.1093/ps/83.7.1093. PMID:15285498.

Annett, C.B., Viste, J.R., Chirino-Trejo, M., Classen, H.L., Middleton, D.M., and Simko, E. 2002. Necrotic enteritis: effect of barley, wheat and corn diets on proliferation of Clostridium perfringens type A. Avian Pathol. 31: 598-601. doi:10.1080/0307945021000024544. PMID:12593744.

Antoniou, T., Marquardt, R.R., and Cansfield, P.E. 1981. Isolation, partial characterization, and antinutritional activity of a factor (pentosans) in rye grain. J. Agric. Food Chem. 29: 1240-1247. doi:10.1021/jf00108a035. PMID:7320340.

Antoniou, T.C., and Marquardt, R.R. 1982. Utilization of rye diets by chicks as affected by lipid type and level and penicillin supplementation. Poult. Sci. 61: 107-116. doi:10.3382/ ps.0610107.

Antonissen, G., Croubels, S., Pasmans, F., Ducatelle, R., Eeckhaut, V., Devreese, M., et al. 2015. Fumonisins affect the intestinal microbial homeostasis in broiler chickens, predisposing to necrotic enteritis. Vet. Res. 46: 98. doi:10.1186/ s13567-015-0234-8. PMID:26394675.

Apajalahti, J., and Vienola, K. 2016. Interaction between chicken intestinal microbiota and protein digestion. Anim. Feed Sci. Technol. 221: 323-330. doi:10.1016/j.anifeedsci.2016.05.004.

Apajalahti, J., Kettunen, A., and Graham, H. 2004. Characteristics of the gastrointestinal microbial communities, with special reference to the chicken. World's Poult. Sci. J. 60: 223-232. doi:10.1079/WPS20040017.

Askelson, T.E., Flores, C.A., Dunn-Horrocks, S.L., Dersjant-Li, Y., Gibbs, K., Awati, A., et al. 2018. Effects of direct-fed microorganisms and enzyme blend co-administration on intestinal bacteria in broilers fed diets with or without antibiotics. Poult. Sci. 97: 54-63.

Augustine, P., McNaughton, J., Virtanen, E., and Rosi, L. 1997. Effect of betaine on the growth performance of chicks inoculated with mixed cultures of avian Eimeria species and on invasion and development of Eimeria tenella and Eimeria acervulina in vitro and in vivo. Poult. Sci. 76: 802-809. doi:10.1093/ps/76.6.802. PMID:9181611.

Awad, W.A., Ghareeb, K., and Böhm, J. 2012. The toxicity of Fusarium mycotoxin deoxynivalenol in poultry feeding. World's Poult. Sci. J. 68: 651-668. doi:10.1017/S004393 3912000797.

Awad, W.A., Böhm, J., Razzazi-Fazeli, E., and Zentek, J. 2006. Effects of feeding deoxynivalenol contaminated wheat on growth performance, organ weights and histological parameters of the intestine of broiler chickens. J. Anim. Physiol. Anim. Nutr. 90: 32-37. doi:10.1111/j.1439-0396.2005.00616.x.

Awad, W.A., Ghareeb, K., Abdel-Raheem, S., and Bohm, J. 2009. Effects of dietary inclusion of probiotic and synbiotic on growth performance, organ weights, and intestinal histomorphology of broiler chickens. Poult. Sci. 88: 49-56. doi:10.3382/ps.2008-00244. PMID:19096056.

Bailey, J.S., and Cosby, D.E. 2005. Salmonella prevalence in free-range and certified organic chickens. J. Food. Prot. 68: 2451-2453. doi:10.4315/0362-028X-68.11.2451. PMID:16300088. 
Bailey, M.A., Taylor, R.M., Brar, J.S., Corkran, S.C., Velásquez, C., Novoa Rama, E., et al. 2019. Prevalence and antimicrobial resistance of Campylobacter from antibiotic-free broilers during organic and conventional processing. Poult. Sci. 98: 1447-1454. doi:10.3382/ps/pey486. PMID:30325456.

Bains, B.S. 1980. Lasalocid efficacy in the prevention of coccidiosis of broiler chickens under floor pen conditions. Poult. Sci. 59: 63-68. doi:10.3382/ps.0590063.

Barton, T.L. 1996. Relevance of water quality to broiler and turkey performance. Poult. Sci. 75: 854-856. doi:10.3382/ ps.0750854. PMID:8805202.

Baurhoo, B., Ferket, P.R., and Zhao, X. 2009. Effects of diets containing different concentrations of mannanoligosaccharide or antibiotics on growth performance, intestinal development, cecal and litter microbial populations, and carcass parameters of broilers. Poult. Sci. 88: 2262-2272. doi:10.3382/ps.2008-00562. PMID:19834074.

Bedford, M. 2000a. Removal of antibiotic growth promoters from poultry diets: implications and strategies to minimise subsequent problems. World's Poult. Sci. J. 56: 347-365. doi:10.1079/WPS20000024.

Bedford, M.R. 2000b. Exogenous enzymes in monogastric nutrition - their current value and future benefits. Anim. Feed Sci. Technol. 86: 1-13. doi:10.1016/S0377-8401(00)00155-3.

Běhal, V. 2006. Mode of action of microbial bioactive metabolites. Folia Microbiol. 51: 359-369. doi:10.1007/BF02931577. PMID:17176753.

Belote, B.L., Tujimoto-Silva, A., Hümmelgen, P.H., Sanches, A.W.D., Wammes, J.C.S., Hayashi, R.M., and Santin, E. 2018. Histological parameters to evaluate intestinal health on broilers challenged with Eimeria and Clostridium perfringens with or without enramycin as growth promoter. Poult. Sci. 97: 2287-2294. doi:10.3382/ps/pey064. PMID:29660058.

Biely, J., and March, B.E. 1959. The response of chicks to several antibiotics in different diets and environments. Poult. Sci. 38: 771-774. doi:10.3382/ps.0380771.

Bjerrum, L., Pedersen, K., and Engberg, R.M. 2005. The influence of whole wheat feeding on salmonella infection and gut flora composition in broilers. Avian Dis. 49: 9-15. doi:10.1637/7223061504R. PMID:15839406.

Blake, D.P., Knox, J., Dehaeck, B., Huntington, B., Rathinam, T., Ravipati, V., et al. 2020. Re-calculating the cost of coccidiosis in chickens. Vet. Res. (Paris), 51: 1-115. doi:10.1186/s13567-02000837-2. PMID:32928271.

Bockstael, K., and Van Aerschot, A. 2009. Antimicrobial resistance in bacteria. Cent. Eur. J. Med. 4: 141-155.

Borda-Molina, D., Seifert, J., and Camarinha-Silva, A. 2018. Current perspectives of the chicken gastrointestinal tract and its microbiome. Comput. Struct. Biotechnol. J. 16: 131-139. doi:10.1016/j.csbj.2018.03.002. PMID:30026889.

Botsoglou, N.A., Florou-Paneri, P., Christaki, E., Fletouris, D.J., and Spais, A.B. 2002. Effect of dietary oregano essential oil on performance of chickens and on iron-induced lipid oxidation of breast, thigh and abdominal fat tissues. Br. Poult. Sci. 43: 223-230. doi:10.1080/00071660120121436. PMID:12047086.

Bourassa, D.V., Wilson, K.M., Ritz, C.R., Kiepper, B.K., and Buhr, R.J. 2018. Evaluation of the addition of organic acids in the feed and/or water for broilers and the subsequent recovery of Salmonella Typhimurium from litter and ceca. Poult. Sci. 97: 64-73. doi:10.3382/ps/pex289. PMID:29136237.

Bray, J.L., Taylor, C.S., Cherry, T.E., and Carey, J. 2009. Performance comparison between the use and nonuse of an enteric health medication program across five consecutive commercial broiler flocks. J. Appl. Poult. Res. 18: 165-171. doi:10.3382/japr.2008-00088.

Brenes, A., Smith, M., Guenter, W., and Marquardt, R.R. 1993. Effect of enzyme supplementation on the performance and digestive tract size of broiler chickens fed wheat- and barley-based diets. Poult. Sci. 72: 1731-1739. doi:10.3382/ ps.0721731. PMID:8234133.

Brock, T.D. 1963. Effect of antibiotics and inhibitors on $\mathrm{m}$ protein synthesis. J. Bacteriol. Res. 85: 527. doi:10.1128/JB.85.3. 527-531.1963.

Broom, L.J. 2015. Organic acids for improving intestinal health of poultry. World's Poult. Sci. J. 71: 630-642. doi:10.1017| S0043933915002391.

Broom, L.J. 2017. Necrotic enteritis; current knowledge and dietrelated mitigation. World's Poult. Sci. J. 73: 281-292. doi:10.1017/S0043933917000058.

Bryan, D.D.S.L., Abbott, D.A., Van Kessel, A.G., and Classen, H.L. 2019. In vivo digestion characteristics of protein sources fed to broilers. Poult. Sci. 98: 3313-3325. doi:10.3382/ps/pez067. PMID:30805640.

Bywater, R.J. 2005. Identification and surveillance of antimicrobial resistance dissemination in animal production. Poult. Sci. 84: 644-648. doi:10.1093/ps/84.4.644. PMID:15844823.

Cabahug, S., Ravindran, V., Selle, P.H., and Bryden, W.L. 1999. Response of broiler chickens to microbial phytase supplementation as influenced by dietary phytic acid and non-phytate phosphorus contents. I. Effects on bird performance and toe ash. Br. Poult. Sci. 40: 660-666. doi:10.1080/ 00071669987052. PMID:10670679.

Cant, J.P., McBride, B.W., and Croom, W.J. 1996. The regulation of intestinal metabolism and its impact on whole animal energetics. J. Anim. Sci. 74: 2541-2553. doi:10.2527| 1996.74102541x. PMID:8904723.

Cao, G.T., Zeng, X.F., Chen, A.G., Zhou, L., Zhang, L., Xiao, Y.P., and Yang, C.M. 2013. Effects of a probiotic, Enterococcus faecium, on growth performance, intestinal morphology, immune response, and cecal microflora in broiler chickens challenged with Escherichia coli K88. Poult. Sci. 92: 2949-2955. doi:10.3382/ps.2013-03366. PMID:24135599.

Castanon, J.I.R. 2007. History of the use of antibiotic as growth promoters in European poultry feeds. Poult. Sci. 86: 2466-2471. doi:10.3382/ps.2007-00249. PMID:17954599.

Cervantes, H.M. 2015. Antibiotic-free poultry production: is it sustainable? J. Appl. Poult. Res. 24: 91-97. doi:10.3382/japr/ pfv006.

Chicken Farmers of Canada (CFC). 2018. Chicken Farmers of Canada AMU Strategy. A prescription for change. [Online]. Available from: https://www.chickenfarmers.ca/wp-content/ uploads/2018/01/AMU-Magazine_ENG_web-2.pdf.

Chicken Farmers of Canada (CFC). 2019. Chicken Farmers of Canada 2019 Annual Report. [Online]. Available from: https:/| www.chickenfarmers.ca/wp-content/uploads/2020/04/Annualreport-2019-\%E2\%80\%93-E-Web2.pdf.

Chicken Farmers of Canada (CFC). 2020. Chicken Farmers of Canada 2020 Annual Report. [Online]. Available from: https:// www.chickenfarmers.ca/wp-content/uploads/2021/03/Annualreport-2020-\%E2\%80\%93-E-final-lr.pdf.

Canadian Food Inspection Agency (CFIA). 2020. Index of medicating ingredients by brand name. [Online]. Available from: https://www.inspection.gc.ca/animal-health/livestock-feeds/ medicating-ingredients/mib/brand-name/eng/1331238160681/ 1331238227767.

Chan, G., Guthrie, A., Sockett, P., Wilson, J., Moody, R., and Clark, S. 2015. Economic cost-benefit analysis of the use of bacitracin methylene disalicylate in broilers affected with necrotic enteritis. J. Appl. Poult. Res. 25: 74-79. doi:10.3382/ japr/pfv067.

Chapman, H.D. 2014. Milestones in avian coccidiosis research: a review. Poult. Sci. 93: 501-511. doi:10.3382/ps.2013-03634. PMID:24604841.

Chapman, H.D., Jeffers, T.K., and Williams, R.B. 2010. Forty years of monensin for the control of coccidiosis in poultry. 
Poult. Sci. 89: 1788-1801. doi:10.3382/ps.2010-00931. PMID:20709963.

Chen, J., Tellez, G., Richards, J.D., and Escobar, J. 2015. Identification of potential biomarkers for gut barrier failure in broiler chickens. Front. Vet. Sci. 2: 14. doi:10.3389/ fvets.2015.00014. PMID:26664943.

Chi, M.S., Mirocha, C.J., Kurtz, H.J., Weaver, G., Bates, F., and Shimoda, W. 1977. Subacute toxicity of T-2 toxin in broiler chicks. Poult. Sci. 56: 306-313. doi:10.3382/ps.0560306. PMID:605011.

Choct, M. 2009. Managing gut health through nutrition. Br. Poult. Sci. 50: 9-15. doi:10.1080/00071660802538632. PMID:19234925.

Choct, M., Hughes, R., and Bedford, M. 1999. Effects of a xylanase on individual bird variation, starch digestion throughout the intestine, and ileal and caecal volatile fatty acid production in chickens fed wheat. Br. Poult. Sci. 40: 419-422. doi:10.1080/ 00071669987548. PMID:10475642.

Chowdhury, S.R., and Smith, T.K. 2004. Effects of feeding blends of grains naturally contaminated with Fusarium mycotoxins on performance and metabolism of laying hens. Poult. Sci. 83: 1849-1856. doi:10.1093/ps/83.11.1849. PMID:15554061.

Clavijo, V., and Florez, M.J.V. 2018. The gastrointestinal microbiome and its association with the control of pathogens in broiler chicken production: a review. Poult. Sci. 97: 1006-1021. doi:10.3382/ps/pex359. PMID:29253263.

Coates, M.E., Davies, M.K., and Kon, S.K. 1955. The effect of antibiotics on the intestine of the chick. Br. J. Nutr. 9: 110-119. doi:10.1079/BJN19550016. PMID:14351666.

Coates, M.E., Fuller, R., Harrison, G.F., Lev, M., and Suffolk, S.F. 1963. A comparision of the growth of chicks in the Gustafsson germ-free apparatus and in a conventional environment, with and without dietary supplements of penicillin. Br. J. Nutr. 17: 141-150. doi:10.1079/BJN19630015. PMID:14021819.

Combs, G.F., and Bossard, E.H. 1963. Comparison of growth response of chicks to virginiamycin and other antibiotics. Poult. Sci. 42: 681-685. doi:10.3382/ps.0420681.

Cowieson, A.J., Acamovic, T., and Bedford, M.R. 2003. The effect of phytase and phytic acid on endogenous losses from broiler chickens. Br. Poult. Sci. 44: 23-24. doi:10.1080/713655276.

Cowieson, A.J., Acamovic, T., and Bedford, M.R. 2004. The effects of phytase and phytic acid on the loss of endogenous amino acids and minerals from broiler chickens. Br. Poult. Sci. 45: 101-108. doi:10.1080/00071660410001668923. PMID:15115207.

Cowieson, A.J., Acamovic, T., and Bedford, M.R. 2006. Phytic acid and phytase: implications for protein utilization by poultry. Poult. Sci. 85: 878-885. doi:10.1093/ps/85.5.878. PMID:16673766.

Cowieson, A.J., Ravindran, V., and Selle, P.H. 2008. Influence of dietary phytic acid and source of microbial phytase on ileal endogenous amino acid flows in broiler chickens. Poult. Sci. 87: 2287-2299. doi:10.3382/ps.2008-00096. PMID:18931180.

Cravens, R.L., Goss, G.R., Chi, F., DeBoer, E.D., Davis, S.W., Hendrix, S.M., and Johnston, S.L. 2015. Products to alleviate the effects of necrotic enteritis and aflatoxin on growth performance, lesion scores, and mortality in young broilers. J. Appl. Poult. Res. 24: 145-156. doi:10.3382/japr/pfv015.

Cravens, R.L., Goss, G.R., Chi, F., De Boer, E.D., Davis, S.W., Hendrix, S.M., et al. 2013. The effects of necrotic enteritis, aflatoxin B1, and virginiamycin on growth performance, necrotic enteritis lesion scores, and mortality in young broilers. Poult. Sci. 92: 1997-2004. doi:10.3382/ps.2013-03011. PMID:23873546.

Cross, D.E., McDevitt, R.M., Hillman, K., and Acamovic, T. 2007. The effect of herbs and their associated essential oils on performance, dietary digestibility and gut microflora in chickens from 7 to 28 days of age. Br. Poult. Sci. 48: 496506. doi:10.1080/00071660701463221. PMID:17701503.

Dafwang, I.I., Bird, H.R., and Sunde, M.L. 1984. Broiler chick growth response to antibiotics, 1981-1982. Poult. Sci. 63: 1027-1032. doi:10.3382/ps.0631027. PMID:6610176.

Dahlke, F., Ribeiro, A., Kessler, A., Lima, A., and Maiorka, A. 2003. Effects of corn particle size and physical form of the diet on the gastrointestinal structures of broiler chickens. Braz. J. Poult. Sci. 5: 61-67. doi:10.1590/S1516635X2003000100008.

Das, Q., Islam, M.R., Lepp, D., Tang, J., Yin, X., Mats, L., et al. 2020. Gut microbiota, blood metabolites, and spleen immunity in broiler chickens fed berry pomaces and phenolicenriched extractives. Front. Vet. Sci. 7: 150. doi:10.3389/ fvets.2020.00150. PMID:33134328.

De Cesare, A., Faria do Valle, I., Sala, C., Sirri, F., Astolfi, A., Castellani, G., and Manfreda, G. 2019. Effect of a low protein diet on chicken ceca microbiome and productive performances. Poult. Sci. 98: 3963-3976. doi:10.3382/ps/pez132. PMID:30953072.

De Meyer, F., Eeckhaut, V., Ducatelle, R., Dhaenens, M., Daled, S., Dedeurwaerder, A., et al. 2019. Host intestinal biomarker identification in a gut leakage model in broilers. Vet. Res. 50: 46. doi:10.1186/s13567-019-0663-x. PMID:31215487.

Diarra, M.S., and Malouin, F. 2014. Antibiotics in Canadian poultry productions and anticipated alternatives. Front. Microbiol. 5: 282. doi:10.3389/fmicb.2014.00282. PMID:24987390.

Diarrassouba, F., Diarra, M.S., Bach, S., Delaquis, P., Pritchard, J., Topp, E., and Skura, B.J. 2007. Antibiotic resistance and virulence genes in commensal Escherichia coli and Salmonella isolates from commercial broiler chicken farms. J. Food Prot. 70: 1316-1327. doi:10.4315/0362-028X-70.6.1316. PMID:17612058.

Diaz-Sanchez, S., D’Souza, D., Biswas, D., and Hanning, I. 2015. Botanical alternatives to antibiotics for use in organic poultry production1. Poult. Sci. 94: 1419-1430. doi:10.3382/ps/ pev014. PMID:25743421.

Dibner, J.J., and Buttin, P. 2002. Use of organic acids as a model to study the impact of gut microflora on nutrition and metabolism. J. Appl. Poult. Res. 11: 453-463. doi:10.1093/japr/ 11.4.453.

Dibner, J.J., and Richards, J.D. 2005. Antibiotic growth promoters in agriculture: history and mode of action. Poult. Sci. 84: 634-643. doi:10.1093/ps/84.4.634. PMID:15844822.

Doyle, M.P., and Erickson, M.C. 2006. Reducing the carriage of foodborne pathogens in livestock and poultry. Poult. Sci. 85: 960-973. doi:10.1093/ps/85.6.960. PMID:16776463.

Drew, M.D., Syed, N.A., Goldade, B.G., Laarveld, B., and Van Kessel, A.G. 2004. Effects of dietary protein source and level on intestinal populations of Clostridium perfringens in broiler chickens. Poult. Sci. 83: 414-420. doi:10.1093/ps/83.3.414. PMID:15049494.

Drlica, K., Malik, M., Kerns, R.J., and Zhao, X. 2008. Quinolonemediated bacterial death. Antimicrob. Agents Chemother. 52: 385-392. doi:10.1128/AAC.01617-06. PMID:17724149.

Du, E., Wang, W., Gan, L., Li, Z., Guo, S., and Guo, Y. 2016. Effects of thymol and carvacrol supplementation on intestinal integrity and immune responses of broiler chickens challenged with Clostridium perfringens. J. Anim. Sci. Biotechnol. 7: 19-29. doi:10.1186/s40104-016-0079-7. PMID:27006768.

Ducatelle, R., Goossens, E., De Meyer, F., Eeckhaut, V., Antonissen, G., Haesebrouck, F., and Van Immerseel, F. 2018. Biomarkers for monitoring intestinal health in poultry: present status and future perspectives. Vet. Res. 49: 43-52. doi:10.1186/s13567-018-0538-6. PMID:29739469.

Dusel, G., Kluge, H., Jeroch, H., and Simon, O. 1998. Xylanase supplementation of wheat-based rations for broilers: 
influence of wheat characteristics. J. Appl. Poult. Res. 7: 119131. doi:10.1093/japr/7.2.119.

Eichner, G., Vieira, S.L., Torres, C.A., Coneglian, J.L.B., Freitas, D.M., and Oyarzabal, O.A. 2007. Litter moisture and footpad dermatitis as affected by diets formulated on an all-vegetable basis or having the inclusion of poultry by-product. J. Appl. Poult. Res. 16: 344-350. doi:10.1093/japr/16.3.344.

Elhassan, M.M.O., Ali, A.M., Blanch, A., Kehlet, A.B., and Madekurozwa, M.-C. 2018. Morphological responses of the small intestine of broiler chicks to dietary supplementation with a probiotic, acidifiers, and their combination. J. Appl. Poult. Res. 28: 108-117. doi:10.3382/japr/pfy042.

Elsaidy, N., Mohamed, R.A., and Abouelenien, F. 2015. Assessment of variable drinking water sources used in Egypt on broiler health and welfare. Vet. World, 8: 855-864. doi:10.14202/vetworld.2015.855-864. PMID:27047165.

Emami, N.K., Daneshmand, A., Naeini, S.Z., Graystone, E.N., and Broom, L.J. 2017. Effects of commercial organic acid blends on male broilers challenged with E. coli K88: performance, microbiology, intestinal morphology, and immune response. Poult. Sci. 96: 3254-3263. doi:10.3382/ps/pex106. PMID:28453753.

Engberg, R.M., Hedemann, M.S., and Jensen, B.B. 2002. The influence of grinding and pelleting of feed on the microbial composition and activity in the digestive tract of broiler chickens. Br. Poult. Sci. 43: 569-579. doi:10.1080/ 0007166022000004480. PMID:12365514.

Engster, H.M., Marvil, D., and Stewart-Brown, B. 2002. The effect of withdrawing growth promoting antibiotics from broiler chickens: a long-term commercial industry study. J. Appl. Poult. Res. 11: 431-436. doi:10.1093/japr/11.4.431.

Eyssen, H. 1962. The additive effects of nucleic acids and antibiotics as individual growth promotants for chicks. Poult. Sci. 41: $1822-1828$. doi:10.3382/ps.0411822.

Eyssen, H., and De Somer, P. 1963. Effect of antibiotics on growth and nutrient absorption of chicks. Poult. Sci. 42: 1373-1379. doi:10.3382/ps.0421373.

Fasina, Y.O., Newman, M.M., Stough, J.M., and Liles, M.R. 2016. Effect of Clostridium perfringens infection and antibiotic administration on microbiota in the small intestine of broiler chickens. Poult. Sci. 95: 247-260. doi:10.3382/ps/pev329. PMID:26567176.

Feng, J., Liu, X., Xu, Z.R., Wang, Y.Z., and Liu, J.X. 2007. Effects of fermented soybean meal on digestive enzyme activities and intestinal morphology in broilers. Poult. Sci. 86: 1149-1154. doi:10.1093/ps/86.6.1149. PMID:17495085.

Fetterer, R.H., Augustine, P.C., Allen, P.C., and Barfield, R.C. 2003. The effect of dietary betaine on intestinal and plasma levels of betaine in uninfected and coccidia-infected broiler chicks. Parasitol. Res. 90: 343-348. doi:10.1007/s00436-0030864-z. PMID:12700979.

Frankel, W.L., Zhang, W., Singh, A., Klurfeld, D.M., Don, S., Sakata, T., Modlin, I., and Rombeau, J.L. 1994. Mediation of the trophic effects of short-chain fatty acids on the rat jejunum and colon. Gastroenterology, 106: 375-380. doi:10.1016/ 0016-5085(94)90595-9. PMID:8299904.

Gaskins, H.R., Collier, C.T., and Anderson, D.B. 2002. Antibiotics as growth promotants: mode of action. Anim. Biotechnol. 13: 29-42. doi:10.1081/ABIO-120005768. PMID:12212942.

Gaucher, M.L., Quessy, S., Letellier, A., Arsenault, J., and Boulianne, M. 2015. Impact of a drug-free program on broiler chicken growth performances, gut health, Clostridium perfringens and Campylobacter jejuni occurrences at the farm level. Poult. Sci. 94: 1791-1801. doi:10.3382/ps/ pev142. PMID:26047674.

Georgopapadakou, N.H., Bertasso, A., Chan, K.K., Chapman, J.S., Cleeland, R., Cummings, L.M., et al. 1989. Mode of action of the dual-action cephalosporin Ro 23-9424. Antimicrob.
Agents Chemother. 33: 1067. doi:10.1128/AAC.33.7.1067. PMID:2675755.

Ghareeb, K., Awad, W.A., Böhm, J., and Zebeli, Q. 2015. Impacts of the feed contaminant deoxynivalenol on the intestine of monogastric animals: poultry and swine. J. Appl. Toxicol. 35: 327-337. doi:10.1002/jat.3083. PMID:25352520.

Ghuysen, J.M., Frère, J.M., Leyh-Bouille, M., Coyette, J., Dusart, J., and Nguyen-Distèche, M. 1979. Use of model enzymes in the determination of the mode of action of penicillins and $\Delta$ 3-cephalosporins. Annu. Rev. Biochem. 48: 73-101. doi:10.1146/annurev.bi.48.070179.000445.

Goatcher, W.D., and McGinnis, J. 1972. Influence of beans, peas and lentils as dietary ingredients on the growth response of chicks to antibiotic and methionine supplementation of the diet. Poult. Sci. 51: 440-443. doi:10.3382/ps.0510440. PMID:4643118.

Golden, C.E., and Mishra, A. 2020. Prevalence of Salmonella and Campylobacter spp. in alternative and conventionally produced chicken in the United States: a systematic review and meta-analysis. J. Food Prot. 83: 1181-1197. doi:10.4315/JFP-19538. PMID:32294168.

Goo, D., Kim, J.H., Choi, H.S., Park, G.H., Han, G.P., and Kil, D.Y. 2019. Effect of stocking density and sex on growth performance, meat quality, and intestinal barrier function in broiler chickens. Poult. Sci. 98: 1153-1160. doi:10.3382/ps/ pey491. PMID:30329115.

Goodarzi Boroojeni, F., Svihus, B., Graf von Reichenbach, H., and Zentek, J. 2016. The effects of hydrothermal processing on feed hygiene, nutrient availability, intestinal microbiota and morphology in poultry - a review. Anim. Feed Sci. Technol. 220: 187-215. doi:10.1016/j.anifeedsci.2016.07.010.

Greer, K. 2016. Antibiotic use in U.S. livestock production. Nova Science Publishers, Inc., Hauppauge, NY, USA.

Groschke, A.C., and Evans, R.J. 1950. Effect of antibiotics, synthetic vitamins, vitamin B12 and an APF supplement on chick growth. Poult. Sci. 29: 616-618. doi:10.3382/ps.0290616.

Haberecht, S., Bajagai, Y.S., Moore, R.J., Van, T.T.H., and Stanley, D. 2020. Poultry feeds carry diverse microbial communities that influence chicken intestinal microbiota colonisation and maturation. AMB Express, 10: 1-10. doi:10.1186/s13568020-01077-5.

Harrington, D., Sims, M., and Kehlet, A.B. 2016. Effect of Bacillus subtilis supplementation in low energy diets on broiler performance. J. Appl. Poult. Res. 25: 29-39. doi:10.3382/japr/ pfv057.

Haselmeyer, A., Zentek, J., and Chizzola, R. 2015. Effects of thyme as a feed additive in broiler chickens on thymol in gut contents, blood plasma, liver and muscle. J. Sci. Food Agric. 95: 504-508. doi:10.1002/jsfa.6758. PMID:24862829.

Hashemipour, H., Kermanshahi, H., Golian, A., and Veldkamp, T. 2013. Effect of thymol and carvacrol feed supplementation on performance, antioxidant enzyme activities, fatty acid composition, digestive enzyme activities, and immune response in broiler chickens. Poult. Sci. 92: 2059-2069. doi:10.3382/ps.2012-02685. PMID:23873553.

He, X., Lu, Z., Ma, B., Zhang, L., Li, J., Jiang, Y., et al. 2018. Effects of chronic heat exposure on growth performance, intestinal epithelial histology, appetite-related hormones and genes expression in broilers. J. Sci. Food Agric. 98: 4471-4478. doi:10.1002/jsfa.8971. PMID:29457848.

Heminthavong, K. 2015. Canada's supply management system. Canadian Electronic Library, Ottawa, ON, Canada.

Heo, J.M., Opapeju, F.O., Pluske, J.R., Kim, J.C., Hampson, D.J., and Nyachoti, C.M. 2013. Gastrointestinal health and function in weaned pigs: a review of feeding strategies to control post-weaning diarrhoea without using in-feed antimicrobial compounds. J. Anim. Physiol. Anim. Nutr. (Berl), 97: 207-237. doi:10.1111/j.1439-0396.2012.01284.x. 
Hernández, F., Madrid, J., García, V., Orengo, J., and Megías, M.D. 2004. Influence of two plant extracts on broilers performance, digestibility, and digestive organ size. Poult. Sci. 83: 169-174. doi:10.1093/ps/83.2.169. PMID:14979566.

Heuer, O.E., Pedersen, K., Andersen, J.S., and Madsen, M. 2001. Prevalence and antimicrobial susceptibility of thermophilic Campylobacter in organic and conventional broiler flocks. Lett. Appl. Microbiol. 33: 269-274. doi:10.1046/j.1472765X.2001.00994.x. PMID:11559399.

Hofacre, C.L., Smith, J.A., and Mathis, G.F. 2018. An optimist's view on limiting necrotic enteritis and maintaining broiler gut health and performance in today's marketing, food safety, and regulatory climate. Poult. Sci. 97: 1929-1933. doi:10.3382/ps/pey082. PMID:29762789.

Hoffmann, D., Thurner, S., Ankerst, D., Damme, K., Windisch, W., and Brugger, D. 2019. Chickens' growth performance and pancreas development exposed to soy cake varying in trypsin inhibitor activity, heat-degraded lysine concentration, and protein solubility in potassium hydroxide. Poult. Sci. 98: 2489-2499. doi:10.3382/ps/pey592. PMID:30668825.

Houshmand, M., Azhar, K., Zulkifli, I., Bejo, M.H., and Kamyab, A. 2011. Effects of nonantibiotic feed additives on performance, nutrient retention, gut $\mathrm{pH}$, and intestinal morphology of broilers fed different levels of energy. J. Appl. Poult. Res. 20: 121-128. doi:10.3382/japr.2010-00171.

Houshmand, M., Azhar, K., Zulkifli, I., Bejo, M.H., and Kamyab, A. 2012. Effects of prebiotic, protein level, and stocking density on performance, immunity, and stress indicators of broilers. Poult. Sci. 91: 393-401. doi:10.3382/ps.2010-01050. PMID:22252353.

Huang, D.S., Li, D.F., Xing, J.J., Ma, Y.X., Li, Z.J., and Lv, S.Q. 2006. Effects of feed particle size and feed form on survival of Salmonella Typhimurium in the alimentary tract and cecal S. Typhimurium reduction in growing broilers. Poult. Sci. 85: 831-836. doi:10.1093/ps/85.5.831. PMID:16673759.

Humer, E., Schwarz, C., and Schedle, K. 2015. Phytate in pig and poultry nutrition. J. Anim. Physiol. Anim. Nutr. 99: 605-625. doi:10.1111/jpn.12258. PMID:25405653.

Hutsko, S.L., Meizlisch, K., Wick, M., and Lilburn, M.S. 2016. Early intestinal development and mucin transcription in the young poult with probiotic and mannan oligosaccharide prebiotic supplementation. Poult. Sci. 95: 1173-1178. doi:10.3382/ps/pew019. PMID:26944966.

Izat, A.L., Thomas, R.A., and Adams, M.H. 1989. Effects of dietary antibiotic treatment on yield of commercial broilers. Poult. Sci. 68: 651-655. doi:10.3382/ps.0680651.

Izat, A.L., Colberg, M., Reiber, M.A., Adams, M.H., Skinner, J.T., Cabel, M.C., et al. 1991. Comparison of different anticoccidials on processing characteristics and parts yield of broiler chickens. Poult. Sci. 70: 1419-1423. doi:10.3382/ps.0701419. PMID:1886848.

Jacquier, V., Nelson, A., Jlali, M., Rhayat, L., Brinch, K.S., and Devillard, E. 2019. Bacillus subtilis 29784 induces a shift in broiler gut microbiome toward butyrate-producing bacteria and improves intestinal histomorphology and animal performance. Poult. Sci. 98: 2548-2554. doi:10.3382/ps/pey602. PMID:30668816.

Jang, I.S., Ko, Y.H., Kang, S.Y., and Lee, C.Y. 2007. Effect of a commercial essential oil on growth performance, digestive enzyme activity and intestinal microflora population in broiler chickens. Anim. Feed Sci. Technol. 134: 304-315. doi:10.1016/j.anifeedsci.2006.06.009.

Jayaraman, S., Das, P.P., Saini, P.C., Roy, B., and Chatterjee, P.N. 2017. Use of Bacillus subtilis PB6 as a potential antibiotic growth promoter replacement in improving performance of broiler birds. Poult. Sci. 96: 2614-2622. doi:10.3382/ps/ pex079. PMID:28482065.
Jazi, V., Ashayerizadeh, A., Toghyani, M., Shabani, A., and Tellez, G. 2018. Fermented soybean meal exhibits probiotic properties when included in Japanese quail diet in replacement of soybean meal. Poult. Sci. 97: 2113-2122. doi:10.3382/ ps/pey071. PMID:29554364.

Jazi, V., Mohebodini, H., Ashayerizadeh, A., Shabani, A., and Barekatain, R. 2019. Fermented soybean meal ameliorates Salmonella Typhimurium infection in young broiler chickens. Poult. Sci. 98: 5648-5660. doi:10.3382/ps/pez338. PMID:31247644.

Jin, L.Z., Ho, Y.W., Abdullah, N., and Jalaludin, S. 1998. Growth performance, intestinal microbial populations, and serum cholesterol of broilers fed diets containing Lactobacillus cultures. Poult. Sci. 77: 1259-1265. doi:10.1093/ps/77.9.1259. PMID:9733111.

Johnston, N.P., and Arscott, G.H. 1974. Effect of a fermentation residue and an antibiotic on growth of chickens fed rations containing corn or wheat. Poult. Sci. 53: 1335-1341. doi:10.3382/ps.0531335.

Jones, F., and Ricke, S. 2003. Observations on the history of the development of antimicrobials and their use in poultry feeds. Poult. Sci. 82: 613-617. doi:10.1093/ps/82.4.613. PMID:12710481.

Jones, K. 2001. Campylobacters in water, sewage and the environment. J. Appl. Microbiol. 90: 68S-79S. doi:10.1046/j.13652672.2001.01355.x. PMID:11422562.

Jukes, H.G., Hill, D.C., and Branion, H.D. 1956. Effect of feeding antibiotics on the intestinal tract of the chick. Poult. Sci. 35: 716-723. doi:10.3382/ps.0350716.

Kaczmarek, S.A., Barri, A., Hejdysz, M., and Rutkowski, A. 2016. Effect of different doses of coated butyric acid on growth performance and energy utilization in broilers. Poult. Sci. 95: 851-859. doi:10.3382/ps/pev382. PMID:26740137.

Kaldhusdal, M., Benestad, S.L., and Løvland, A. 2016. Epidemiologic aspects of necrotic enteritis in broiler chickens - disease occurrence and production performance. Avian Pathol. 45: 271-274. doi:10.1080/03079457.2016.1163521. PMID:26956946.

Kaufmann, W. 1964. The possible implication of a bacterial enzyme in the biochemical mode of action of penicillins on Gram negative bacteria. Biochem. Biophys. Res. Commun. 14: 458-462. doi:10.1016/0006-291X(64)90087-7. PMID:5319843.

Kemp, R., Leatherbarrow, A.J.H., Williams, N.J., Hart, C.A., Clough, H.E., Turner, J., et al. 2005. Prevalence and genetic diversity of Campylobacter spp. in environmental water samples from a 100-square-kilometer predominantly dairy farming area. Appl. Environ. Microbiol. 71: 1876. doi:10.1128/ AEM.71.4.1876-1882.2005. PMID:15812015.

Kettunen, H., Tiihonen, K., Peuranen, S., Saarinen, M.T., and Remus, J.C. 2001. Dietary betaine accumulates in the liver and intestinal tissue and stabilizes the intestinal epithelial structure in healthy and coccidia-infected broiler chicks. Comp. Biochem. Physiol. A Mol. Integr. Physiol. 130: 759-769. doi:10.1016/S1095-6433(01)00410-X. PMID:11691612.

Khattak, F., Ronchi, A., Castelli, P., and Sparks, N. 2013. Effects of natural blend of essential oil on growth performance, blood biochemistry, cecal morphology, and carcass quality of broiler chickens. Poult. Sci. 93: 132-137. doi:10.3382/ ps.2013-03387. PMID:24570432.

Khodambashi Emami, N., Samie, A., Rahmani, H.R., and RuizFeria, C.A. 2012. The effect of peppermint essential oil and fructooligosaccharides, as alternatives to virginiamycin, on growth performance, digestibility, gut morphology and immune response of male broilers. Anim. Feed Sci. Technol. 175: 57-64. doi:10.1016/j.anifeedsci.2012.04.001.

Kiarie, E. 2020. Inherent digestive tract insufficiency in monogastric animals: culpability of the gut microbiome and dietary approaches for optimizing intestinal health. Proc. Animal 
Nutrition Conference of Canada. Virtual. Animal Nutrition Association of Canada (ANAC), Ottawa, ON, Canada.

Kiarie, E., Romero, L.F., and Nyachoti, C.M. 2013. The role of added feed enzymes in promoting gut health in swine and poultry. Nutr. Res. Rev. 26: 71-88. doi:10.1017| S0954422413000048. PMID:23639548.

Kiarie, E., Romero, L.F., and Ravindran, V. 2014. Growth performance, nutrient utilization, and digesta characteristics in broiler chickens fed corn or wheat diets without or with supplemental xylanase. Poult. Sci. 93: 1186-1196. doi:10.3382/ ps.2013-03715. PMID:24795311.

Kiarie, E., Walsh, M.C., and Nyachoti, C.M. 2016. Performance, digestive function, and mucosal responses to selected feed additives for pigs. J. Anim. Sci. 94: 169-180. doi:10.2527| jas.2015-9835.

Kiarie, E., Nyachoti, C.M., Slominski, B.A., and Blank, G. 2007. Growth performance, gastrointestinal microbial activity, and nutrient digestibility in early-weaned pigs fed diets containing flaxseed and carbohydrase enzyme. J. Anim. Sci. 85: 2982-2993. doi:10.2527/jas.2006-481. PMID:17686904.

Kiarie, E., Voth, C., Wey, D., Zhu, C., Vingerhoeds, P., Borucki, S., and Squires, E.J. 2018. Comparative efficacy of antibiotic growth promoter and benzoic acid on growth performance, nutrient utilization, and indices of gut health in nursery pigs fed corn-soybean meal diet. Can. J. Anim. Sci. 98: 868-874. doi:10.1139/cjas-2018-0056.

Kiarie, E.G., and Mills, A. 2019. Role of feed processing on gut health and function in pigs and poultry: conundrum of optimal particle size and hydrothermal regimens. Front. Vet. Sci. 6: 19. doi:10.3389/fvets.2019.00019. PMID:30838217 [Review] [English].

Kiarie, E.G., Leung, H., Akbari Moghaddam Kakhki, R., Patterson, R., and Barta, J.R. 2019. Utility of feed enzymes and yeast derivatives in ameliorating deleterious effects of coccidiosis on intestinal health and function in broiler chickens. Front. Vet. Sci. 6: 473. doi:10.3389/fvets.2019.00473. PMID:31921926 [Review] [English].

Kiarie, E.G., Parenteau, I.A., Zhu, C., Ward, N.E., and Cowieson, A.J. 2020. Digestibility of amino acids, energy, and minerals in roasted full-fat soybean and expelled-extruded soybean meal fed to growing pigs without or with multienzyme supplement containing fiber-degrading enzymes, protease, and phytase. J. Anim. Sci. 98: 1-10. doi:10.1093/jas/skaa174. PMID:32437583.

Kiarie, E.G., Mohammadigheisar, M., Akbari Moghaddam Kakhki, R., and Madsen, M.H.. 2021. Impact of feeding modified soy protein concentrate in the starter phase on growth performance and gastrointestinal responses in broiler chickens through to day 42 of age. Poult. Sci. 100: 101147. doi:10.1016/j.psj.2021.101147. PMID:33940283.

Klasing, K.C., Adler, K.L., Remus, J.C., and Calvert, C.C. 2002. Dietary betaine increases intraepithelial lymphocytes in the duodenum of coccidia-infected chicks and increases functional properties of phagocytes. J. Nutr. 132: 2274-2282. doi:10.1093/jn/132.8.2274. PMID:12163675.

Koelkebeck, K.W., McKee, J.S., Harrison, P.C., Parsons, C.M., and Zimmerman, R.A. 1999. Performance of laying hens provided water from two sources. J. Appl. Poul. Res. 8: 374-379. doi:10.1093/japr/8.3.374.

Kofoed, C.B., and Vester, B. 2002. Interaction of avilamycin with ribosomes and resistance caused by mutations in 23S rRNA. Antimicrob. Agents Chemother. 46: 3339. doi:10.1128/ AAC.46.11.3339-3342.2002. PMID:12384333.

Kogut, M.H. 2013. The gut microbiota and host innate immunity: regulators of host metabolism and metabolic diseases in poultry? J. Appl. Poult. Res. 22: 637-646. doi:10.3382/ japr.2013-00741.
Kogut, M.H. 2017. Issues and consequences of using nutrition to modulate the avian immune response. J. Appl. Poult. Res. 26: 605-612. doi:10.3382/japr/pfx028.

Kogut, M.H. 2019. The effect of microbiome modulation on the intestinal health of poultry. Anim. Feed Sci. Technol. 250: 32-40. doi:10.1016/j.anifeedsci.2018.10.008.

Kollarcikova, M., Kubasova, T., Karasova, D., Crhanova, M., Cejkova, D., Sisak, F., and Rychlik, I. 2019. Use of 16S rRNA gene sequencing for prediction of new opportunistic pathogens in chicken ileal and cecal microbiota. Poult. Sci. 98: 2347-2353. doi:10.3382/ps/pey594. PMID:30624758.

Kridtayopas, C., Rakangtong, C., Bunchasak, C., and Loongyai, W. 2019. Effect of prebiotic and synbiotic supplementation in diet on growth performance, small intestinal morphology, stress, and bacterial population under high stocking density condition of broiler chickens. Poult. Sci. 98: 4595-4605. doi:10.3382/ps/pez152. PMID:30951594.

Krupkin, M., Wekselman, I., Matzov, D., Eyal, Z., Diskin Posner, Y., Rozenberg, H., et al. 2016. Avilamycin and evernimicin induce structural changes in rProteins uL16 and CTC that enhance the inhibition of A-site tRNA binding. Proc. Natl. Acad. Sci. USA, 113: E6796. doi:10.1073/pnas.1614297113. PMID:27791159.

Lambert, G.P. 2009. Stress-induced gastrointestinal barrier dysfunction and its inflammatory effects. J. Anim. Sci. 87: E101-E108. doi:10.2527/jas.2008-1339. PMID:18791134.

Latorre, J.D., Hernandez-Velasco, X., Bielke, L.R., Vicente, J.L., Wolfenden, R., Menconi, A., et al. 2015. Evaluation of a Bacillus direct-fed microbial candidate on digesta viscosity, bacterial translocation, microbiota composition and bone mineralisation in broiler chickens fed on a rye-based diet. Br. Poult. Sci. 56: 723-732. doi:10.1080/00071668.2015.1101053. PMID:26539833.

LaVorgna, M., Schaeffer, J.L., Bade, D., Dickson, J., Cookson, K., and Davis, S.W. 2013. Performance of broilers fed a broader spectrum antibiotic (virginiamycin) or a narrower spectrum antibiotic (bacitracin methylene disalicylate) over 3 consecutive grow-out cycles. J. Appl. Poult. Res. 22: 574-582. doi:10.3382/japr.2012-00703.

Lee, K.W., Everts, H., Kappert, H.J., Frehner, M., Losa, R., and Beynen, A.C. 2003. Effects of dietary essential oil components on growth performance, digestive enzymes and lipid metabolism in female broiler chickens. Br. Poult. Sci. 44: 450-457. doi:10.1080/0007166031000085508. PMID:12964629.

Lee, S., Kim, D.-H., Keum, M.-C., Han, E., An, B.-K., Chang, H.-H., et al. 2017. Effects of fumonisin B1 and mycotoxin binders on growth performance, tibia characteristics, gut physiology, and stress indicators in broiler chickens raised in different stocking densities. Poult. Sci. 97: 845-854. doi:10.3382/ps/ pex382.

Leeson, S., and Summers, J.D. 1997. Commercial poultry nutrition. University Books.

Leeson, S., and Summers, J.D. 2019. Scott's nutrition of the chicken. International Book Distributing Company.

Leeson, S., Namkung, H., Antongiovanni, M., and Lee, E.H. 2005. Effect of butyric acid on the performance and carcass yield of broiler chickens. Poult. Sci. 84: 1418-1422. doi:10.1093/ps/ 84.9.1418. PMID:16206563.

Lei, K., Li, Y.L., Yu, D.Y., Rajput, I.R., and Li, W.F. 2013. Influence of dietary inclusion of Bacillus licheniformis on laying performance, egg quality, antioxidant enzyme activities, and intestinal barrier function of laying hens. Poult. Sci. 92: 2389-2395. doi:10.3382/ps.2012-02686. PMID:23960122.

Leung, H., and Kiarie, E.G. 2020. Standardized ileal digestibility of amino acids and apparent metabolizable energy in corn and soybean meal for organic broiler chicken production in Ontario. Can. J. Anim. Sci. 100: 447-454. doi:10.1139/cjas2019-0166. 
Leung, H., Yitbarek, A., Snyder, R., Patterson, R., Barta, J.R., Karrow, N., and Kiarie, E. 2019. Responses of broiler chickens to Eimeria challenge when fed a nucleotide-rich yeast extract1. Poult. Sci. 98: 1622-1633. doi:10.3382/ps/pey533. PMID:30481335.

Liu, J.D., Secrest, S.A., and Fowler, J. 2017. Computed tomographic precision rate-of-passage assay without a fasting period in broilers: more precise foundation for targeting the releasing time of encapsulated products. Livest. Sci. 200: 60-63. doi:10.1016/j.livsci.2017.04.006.

Liu, J.D., Lumpkins, B., Mathis, G., Williams, S.M., and Fowler, J. 2019. Evaluation of encapsulated sodium butyrate with varying releasing times on growth performance and necrotic enteritis mitigation in broilers. Poult. Sci. 98: 3240-3245. doi:10.3382/ps/pez049. PMID:30789214.

Liu, W.C., and Kim, I.H. 2016. Effects of dietary xylanase supplementation on performance and functional digestive parameters in broilers fed wheat-based diets. Poult. Sci. 96: 566-573. doi:10.3382/ps/pew258.

Loar, R.E., 2nd, Moritz, J.S., Donaldson, J.R., and Corzo, A. 2010. Effects of feeding distillers dried grains with solubles to broilers from 0 to 28 days posthatch on broiler performance, feed manufacturing efficiency, and selected intestinal characteristics. Poult. Sci. 89: 2242-2250. doi:10.3382/ps.201000894. PMID:20852115.

MacAuliffe, T., and McGinnis, J. 1971. Effect of antibiotic supplements to diets containing rye on chick growth. Poult. Sci. 50: 1130-1134. doi:10.3382/ps.0501130. PMID:5095825.

Manafi, M., Hedayati, M., Pirany, N., and Omede, A.A. 2019. Comparison of performance and feed digestibility of the non-antibiotic feed supplement (Novacid) and an antibiotic growth promoter in broiler chickens. Poult. Sci. 98: 904-911. doi:10.3382/ps/pey437. PMID:30285253.

Marquardt, R.R., Ward, A.T., and Misir, R.1979. The retention of nutrients by chicks fed rye diets supplemented with amino acids and penicillin. Poult. Sci. 58: 631-640. doi:10.3382/ ps.0580631.

Massuquetto, A., Panisson, J.C., Marx, F.O., Surek, D., Krabbe, E.L., and Maiorka, A. 2019. Effect of pelleting and different feeding programs on growth performance, carcass yield, and nutrient digestibility in broiler chickens. Poult. Sci. 98: 5497-5503. doi:10.3382/ps/pez176. PMID:30995321.

Matthews, J.O., and Southern, L.L. 2000. The effect of dietary betaine in Eimeria acervulina-infected chicks. Poult. Sci. 79: 60-65. doi:10.1093/ps/79.1.60. PMID:10685890.

McDougald, L.R. 1998. Intestinal protozoa important to poultry. Poult. Sci. 77: 1156-1158. doi:10.1093/ps/77.8.1156. PMID:9706082.

McNaughton, J.L., Reece, F.N., and Deaton, J.W. 1981. Relationships between color, trypsin inhibitor contents, and urease index of soybean meal and effects on broiler performance. Poult. Sci. 60: 393-400. doi:10.3382/ps.0600393.

Metzler-Zebeli, B.U., Eklund, M., and Mosenthin, R. 2009. Impact of osmoregulatory and methyl donor functions of betaine on intestinal health and performance in poultry. World's Poult. Sci. J. 65: 419-442. doi:10.1017/S004393 3909000300.

Mian, M.A., and Garlich, J.D. 1995. Tolerance of turkeys to diets high in trypsin inhibitor activity from undertoasted soybean meals. Poult. Sci. 74: 1126-1133. doi:10.3382/ps.0741126. PMID:7479489.

Mikulski, D., Jankowski, J., Naczmanski, J., Mikulska, M., and Demey, V. 2012. Effects of dietary probiotic (Pediococcus acidilactici) supplementation on performance, nutrient digestibility, egg traits, egg yolk cholesterol, and fatty acid profile in laying hens. Poult. Sci. 91: 2691-2700. doi:10.3382/ps.201202370. PMID:22991559.
Milbradt, E.L., Okamoto, A.S., Rodrigues, J.C., Garcia, E.A., Sanfelice, C., Centenaro, L.P., and Andreatti Filho, R.L. 2014. Use of organic acids and competitive exclusion product as an alternative to antibiotic as a growth promoter in the raising of commercial turkeys. Poult. Sci. 93: 1855-1861. doi:10.3382/ps.2013-03593. PMID:24812241.

Miles, R.D., Butcher, G.D., Henry, P.R., and Littell, R.C. 2006. Effect of antibiotic growth promoters on broiler performance, intestinal growth parameters, and quantitative morphology. Poult. Sci. 85: 476-485. doi:10.1093/ps/85.3.476. PMID:16553279.

Missotten, J.A., Michiels, J., Dierick, N., Ovyn, A., Akbarian, A., and De Smet, S. 2013. Effect of fermented moist feed on performance, gut bacteria and gut histo-morphology in broilers. Br. Poult. Sci. 54: 627-634. doi:10.1080/00071668.2013.811718. PMID:23927009.

Mohammadi Gheisar, M., Hosseindoust, A., and Kim, I.H. 2015. Evaluating the effect of microencapsulated blends of organic acids and essential oils in broiler chickens diet. J. Appl. Poult. Res. 24: 511-519. doi:10.3382/japr/pfv063.

Mohammadigheisar, M., Shouldice, V.L., Sands, J.S., Lepp, D., Diarra, M.S., and Kiarie, E.G. 2020. Growth performance, breast yield, gastrointestinal ecology and plasma biochemical profile in broiler chickens fed multiple doses of a blend of red, brown and green seaweeds. Br. Poult. Sci. 61: 590-598. doi:10.1080/00071668.2020.1774512. PMID:32508147.

Mohiti-Asli, M., and Ghanaatparast-Rashti, M. 2017. Comparison of the effect of two phytogenic compounds on growth performance and immune response of broilers. J. Appl. Anim. Res. 45: 603-608. doi:10.1080/09712119.2016.1243119.

Molnar, A.K., Podmaniczky, B., Kurti, P., Tenk, I., Glavits, R., Virag, G., and Szabo, Z. 2011. Effect of different concentrations of Bacillus subtilis on growth performance, carcase quality, gut microflora and immune response of broiler chickens. Br. Poult. Sci. 52: 658-665. PMID:22221231.

Moore, P.R., and Evenson, A. 1946. Use of sulfasuxidine, streptothricin, and streptomycin in nutritional studies with the chick. J. Biol. Chem. 165: 437-441. doi:10.1016/S0021-9258(17) 41154-9. PMID:20276107.

Moore, R.J. 2016. Necrotic enteritis predisposing factors in broiler chickens. Avian Pathol. 45: 275-281. doi:10.1080/ 03079457.2016.1150587. PMID:26926926.

Moquet, P.C.A., Salami, S.A., Onrust, L., Hendriks, W.H., and Kwakkel, R.P. 2018. Butyrate presence in distinct gastrointestinal tract segments modifies differentially digestive processes and amino acid bioavailability in young broiler chickens. Poult. Sci. 97: 167-176. doi:10.3382/ps/pex279. PMID:29077956.

Moquet, P.C.A., Onrust, L., Van Immerseel, F., Ducatelle, R., Hendriks, W.H., and Kwakkel, R.P. 2016. Importance of release location on the mode of action of butyrate derivatives in the avian gastrointestinal tract. World's Poult. Sci. J. 72: 61-80. doi:10.1017/S004393391500269X.

Mountzouris, K.C., Tsirtsikos, P., Kalamara, E., Nitsch, S., Schatzmayr, G., and Fegeros, K. 2007. Evaluation of the efficacy of a probiotic containing lactobacillus, bifidobacterium, enterococcus, and pediococcus strains in promoting broiler performance and modulating cecal microflora composition and metabolic activities. Poult. Sci. 86: 309-317. doi:10.1093/ ps/86.2.309. PMID:17234844.

Mountzouris, K.C., Tsitrsikos, P., Palamidi, I., Arvaniti, A., Mohnl, M., Schatzmayr, G., and Fegeros, K. 2010. Effects of probiotic inclusion levels in broiler nutrition on growth performance, nutrient digestibility, plasma immunoglobulins, and cecal microflora composition. Poult. Sci. 89: 58-67. doi:10.3382/ps.2009-00308. PMID:20008803.

Munyaka, P.M., Nandha, N.K., Kiarie, E., Nyachoti, C.M., and Khafipour, E. 2016. Impact of combined beta-glucanase and 
xylanase enzymes on growth performance, nutrients utilization and gut microbiota in broiler chickens fed corn or wheat-based diets. Poult. Sci. 95: 528-540. doi:10.3382/ps/ pev333. PMID:26574039.

Musigwa, S., Cozannet, P., Morgan, N., Swick, R.A., and Wu, S.-B. 2021. Multi-carbohydrase effects on energy utilization depend on soluble non-starch polysaccharides-to-total non-starch polysaccharides in broiler diets. Poult. Sci. 100: 788-796. doi:10.1016/j.psj.2020.10.038. PMID:33518133.

NFACC. 2016. National Farm Animal Care Council - code of practice. [Online]. Available from: www.nfacc.ca.

Nguyen, D.H., Lee, K.Y., Mohammadigheisar, M., and Kim, I.H. 2018. Evaluation of the blend of organic acids and mediumchain fatty acids in matrix coating as antibiotic growth promoter alternative on growth performance, nutrient digestibility, blood profiles, excreta microflora, and carcass quality in broilers. Poult. Sci. 97: 4351-4358. doi:10.3382/ps/ pey339. PMID:30165535.

Niewold, T.A. 2007. The nonantibiotic anti-inflammatory effect of antimicrobial growth promoters, the real mode of action? A hypothesis. Poult. Sci. 86: 605-609. doi:10.1093/ps/86.4.605. PMID:17369528.

Nir, I., Hillel, R., Ptichi, I., and Shefet, G. 1995. Effect of particle size on performance. 3. Grinding pelleting interactions. Poult. Sci. 74: 771-783. doi:10.3382/ps.0740771. PMID:7603952.

Nyachoti, C.M., Omogbenigun, F.O., Rademacher, M., and Blank, G. 2006. Performance responses and indicators of gastrointestinal health in early-weaned pigs fed low-protein amino acid-supplemented diets. J. Anim. Sci. 84: 125-134. doi:10.2527/2006.841125x. PMID:16361499.

Oakley, B.B., Vasconcelos, E.J.R., Diniz, P., Calloway, K.N., Richardson, E., Meinersmann, R.J., et al. 2018. The cecal microbiome of commercial broiler chickens varies significantly by season. Poult. Sci. 97: 3635-3644. doi:10.3382/ps/ pey214. PMID:30016503.

Oatway, L., Vasanthan, T., and Helm, J.H. 2001. Phytic acid. Food Rev. Int. 17: 419-431. doi:10.1081/FRI-100108531.

Oka, T. 1976. Mode of action of penicillins in vivo and in vitro in Bacillus megaterium. Antimicrob. Agents Chemother. 10: 579-591. doi:10.1128/AAC.10.4.579. PMID:825031.

Oso, A.O., Suganthi, R.U., Reddy, G.B.M., Malik, P.K., Thirumalaisamy, G., Awachat, V.B., et al. 2019. Effect of dietary supplementation with phytogenic blend on growth performance, apparent ileal digestibility of nutrients, intestinal morphology, and cecal microflora of broiler chickens. Poult. Sci. 98: 4755-4766. doi:10.3382/ps/pez191. PMID:30951593.

Palliyeguru, M.W.C.D., Rose, S.P., and Mackenzie, A.M. 2011. Effect of trypsin inhibitor activity in soya bean on growth performance, protein digestibility and incidence of sub-clinical necrotic enteritis in broiler chicken flocks. Br. Poult. Sci. 52: 359-367. doi:10.1080/00071668.2011.577054. PMID:21732882 [English].

Parent, E., Archambault, M., Moore, R.J., and Boulianne, M. 2020. Impacts of antibiotic reduction strategies on zootechnical performances, health control and Eimeria spp. excretion compared to conventional antibiotic programs in commercial broiler chicken flocks. Poult. Sci. 99: 4303-4313. doi:10.1016/j.psj.2020.05.037. PMID:32867974.

Parenteau, I.A., Stevenson, M., and Kiarie, E.G. 2020. Egg production and quality responses to increasing isoleucine supplementation in Shaver white hens fed a low crude protein corn-soybean meal diet fortified with synthetic amino acids between 20 and 46 weeks of age. Poult. Sci. 99: 1444-1453. doi:10.1016/j.psj.2019.10.064. PMID:32111315.

Park, J.H., and Kim, I.H. 2018. Effects of a protease and essential oils on growth performance, blood cell profiles, nutrient retention, ileal microbiota, excreta gas emission, and breast meat quality in broiler chicks. Poult. Sci. 97: 2854-2860. doi:10.3382/ps/pey151. PMID:29788490.

Patel, S.J., Wellington, M., Shah, R.M., and Ferreira, M.J. 2020. Antibiotic stewardship in food-producing animals: challenges, progress, and opportunities. Clin. Ther. 42: 1649-1658. doi:10.1016/j.clinthera.2020.07.004. PMID:32819723.

Pathumnakul, S., Ittiphalin, M., Piewthongngam, K., and Rujikietkumjorn, S. 2011. Should feed mills go beyond traditional least cost formulation? Comput. Electron. Agric. 75: 243-249. doi:10.1016/j.compag.2010.11.009.

Patten, J.D., and Waldroup, P.W. 1988. Use of organic acids in broiler diets. Poult. Sci. 67: 1178-1182. doi:10.3382/ps.0671178. PMID:3217307.

Patterson, J., and Burkholder, K. 2003. Application of prebiotics and probiotics in poultry production. Poult. Sci. 82: 627-631. doi:10.1093/ps/82.4.627. PMID:12710484.

Pedersen, K., Bjerrum, L., Nauerby, B., and Madsen, M. 2003. Experimental infections with rifampicin-resistant Clostridium perfringens strains in broiler chickens using isolator facilities. Avian Patho. 32: 401-408. doi:10.1080/ 0307945031000121158.

Pedersen, K., Bjerrum, L., Heuer, O.E., Lo Fo Wong, D.M.A., and Nauerby, B. 2008. Reproducible infection model for Clostridium perfringens in broiler chickens. Avian Dis. Dig. 3: e18-e18. doi:10.1637/1933-5334(2008)3[e18:RIMFCP]2.0.CO;2.

Pepper, W.F., Slinger, S.J., and Motzok, I. 1953. Effect of aureomycin on the niacin and manganese requirements of chicks. Poult. Sci. 32: 656-660. doi:10.3382/ps.0320656.

Perez, V.G., Jacobs, C.M., Barnes, J., Jenkins, M.C., Kuhlenschmidt, M.S., Fahey, G.C., Jr., et al. 2011. Effect of corn distillers dried grains with solubles and Eimeria acervulina infection on growth performance and the intestinal microbiota of young chicks. Poult. Sci. 90: 958-964. doi:10.3382/ps.2010-01066. PMID:21489939.

Ramlucken, U., Ramchuran, S.O., Moonsamy, G., Lalloo, R., Thantsha, M.S., and Jansen van Rensburg, C. 2020. A novel Bacillus based multi-strain probiotic improves growth performance and intestinal properties of Clostridium perfringens challenged broilers. Poult. Sci. 99: 331-341. doi:10.3382/ps/ pez496. PMID:32416818.

Ravindran, V. 2012. Advances and future directions in poultry nutrition: an overview. Korean J. Poult. Sci. 39: 53-62. doi:10.5536/KJPS.2012.39.1.053.

Ravindran, V., Morel, P.C.H., Partridge, G.G., Hruby, M., and Sands, J.S. 2006. Influence of an Escherichia coli-derived phytase on nutrient utilization in broiler starters fed diets containing varying concentrations of phytic acid. Poult. Sci. 85: 82-89. doi:10.1093/ps/85.1.82. PMID:16493949.

Reis, M.P., Fassani, E.J., Júnior, A.A.P.G., Rodrigues, P.B., Bertechini, A.G., Barrett, N., Persia, M.E., and Schmidt, C.J. 2017. Effect of Bacillus subtilis (DSM 17299) on performance, digestibility, intestine morphology, and pH in broiler chickens. J. Appl. Poult. Res. 26: 573-583. doi:10.3382/japr/pfx032.

Reisinger, N., Steiner, T., Nitsch, S., Schatzmayr, G., and Applegate, T.J. 2011. Effects of a blend of essential oils on broiler performance and intestinal morphology during coccidial vaccine exposure. J. Appl. Poult. Res. 20: 272-283. doi:10.3382/japr.2010-00226.

Rezaeipour, V., and Gazani, S. 2014. Effects of feed form and feed particle size with dietary L-threonine supplementation on performance, carcass characteristics and blood biochemical parameters of broiler chickens. J. Anim. Sci. Technol. 56: 20-20. doi:10.1186/2055-0391-56-20. PMID:26290709.

Ricke, S. 2003. Perspectives on the use of organic acids and short chain fatty acids as antimicrobials. Poult. Sci. 82: 632-639. doi:10.1093/ps/82.4.632. PMID:12710485.

Ritzi, M.M., Abdelrahman, W., van-Heerden, K., Mohnl, M., Barrett, N.W., and Dalloul, R.A. 2016. Combination of 
probiotics and coccidiosis vaccine enhances protection against an Eimeria challenge. Vet. Res. 47: 111. doi:10.1186/ s13567-016-0397-y. PMID:27825377.

Röhe, I., Ruhnke, I., Knorr, F., Mader, A., Boroojeni, F.G., Löwe, R., and Zentek, J. 2014. Effects of grinding method, particle size, and physical form of the diet on gastrointestinal morphology and jejunal glucose transport in laying hens. Poult. Sci. 93: 2060-2068. doi:10.3382/ps.2013-03783. PMID:24902702.

Roto, S.M., Rubinelli, P.M., and Ricke, S.C. 2015. An introduction to the avian gut microbiota and the effects of yeast-based prebiotic-type compounds as potential feed additives. Front. Vet. Sci. 2. doi:10.3389/fvets.2015.00028.

Roto, S.M., Kwon, Y.M., and Ricke, S.C. 2016. Applications of in ovo technique for the optimal development of the gastrointestinal tract and the potential influence on the establishment of its microbiome in poultry. Front. Vet. Sci. 3: 63. doi:10.3389/fvets.2016.00063. PMID:27583251.

Sanchez, J., Thanabalan, A., Khanal, T., Patterson, R., Slominski, B.A., and Kiarie, E. 2019. Growth performance, gastrointestinal weight, microbial metabolites and apparent retention of components in broiler chickens fed up to $11 \%$ rice bran in a corn-soybean meal diet without or with a multi-enzyme supplement. Anim. Nutr. 5: 41-48. doi:10.1016/ j.aninu.2018.12.001. PMID:30899808.

Santi Devi, U. 2017. Efficacy of phytogenic feed additive on performance, production and health status of monogastric animals - a review. Ann. Anim. Sci. 17: 929-948. doi:10.1515/ aoas-2016-0079.

Sarwar Gilani, G., Wu Xiao, C., and Cockell, K.A. 2012. Impact of antinutritional factors in food proteins on the digestibility of protein and the bioavailability of amino acids and on protein quality. Br. J. Nutr. 108: S315-S332. doi:10.1017/ S0007114512002371. PMID:23107545.

Scheurer, W., Spring, P., and Maertens, L. 2013. Effect of 3 dietary phytogenic products on production performance and coccidiosis in challenged broiler chickens. J. Appl. Poult. Res. 22: 591-599. doi:10.3382/japr.2013-00726.

Schofield, E.K. 2005. Feed manufacturing technology V. American Feed Industry Association, Arlington, VA, USA. $670 \mathrm{pp}$.

Seal, B.S., Lillehoj, H.S., Donovan, D.M., and Gay, C.G. 2013. Alternatives to antibiotics: a symposium on the challenges and solutions for animal production. Anim. Health Res. Rev. 14: 78-87. doi:10.1017/S1466252313000030. PMID:23702321.

Shang, Q.H., Liu, S.J., He, T.F., Liu, H.S., Mahfuz, S., Ma, X.K., and Piao, X.S. 2020. Effects of wheat bran in comparison to antibiotics on growth performance, intestinal immunity, barrier function, and microbial composition in broiler chickens. Poult. Sci. 99: 4929-4938. doi:10.1016/j.psj.2020.06.031. PMID:32988529.

Shojadoost, B., Vince, A.R., and Prescott, J.F. 2012. The successful experimental induction of necrotic enteritis in chickens by Clostridium perfringens: a critical review. Vet. Res. (Paris), 43: 74-74. doi:10.1186/1297-9716-43-74.

Singh, P.K. 2008. Significance of phytic acid and supplemental phytase in chicken nutrition: a review. World's Poult. Sci. J. 64: 553-580. doi:10.1017/S0043933908000202.

Skinner, J.T., Izat, A.L., and Waldroup, P.W. 1991. Research note: fumaric acid enhances performance of broiler chickens. Poult. Sci. 70: 1444-1447. doi:10.3382/ps.0701444. PMID:1886851.

Skinner, J.T., Bauer, S., Young, V., Pauling, G., and Wilson, J. 2010. An economic analysis of the impact of subclinical (mild) necrotic enteritis in broiler chickens. Avian Dis. 54: 1237-1240. doi:10.1637/9399-052110-Reg.1. PMID:21313845.

Sklan, D., Klipper, E., Friedman, A., Shelly, M., and Makovsky, B. 2001. The effect of chronic feeding of diacetoxyscirpenol, T-2 toxin, and aflatoxin on performance, health, and antibody production in chicks. J. Appl. Poult. Res. 10: 79-85. doi:10.1093/japr/10.1.79.

Slominski, B.A. 2011. Recent advances in research on enzymes for poultry diets. Poult. Sci. 90: 2013-2023. doi:10.3382/ ps.2011-01372. PMID:21844268.

Smeets, N., Nuyens, F., Van Campenhout, L., Delezie, E., and Niewold, T.A. 2018. Interactions between the concentration of non-starch polysaccharides in wheat and the addition of an enzyme mixture in a broiler digestibility and performance trial. Poult. Sci. 97: 2064-2070. doi:10.3382/ps/pey038. PMID:29471412.

Smith, J.A. 2011. Experiences with drug-free broiler production. Poult. Sci. 90: 2670-2678. doi:10.3382/ps.2010-01032. PMID:22010257.

Song, Y.S., Pérez, V.G., Pettigrew, J.E., Martinez-Villaluenga, C., and de Mejia, E.G. 2010. Fermentation of soybean meal and its inclusion in diets for newly weaned pigs reduced diarrhea and measures of immunoreactivity in the plasma. Anim. Feed Sci. Technol. 159: 41-49. doi:10.1016/j.anifeedsci. 2010.04.011.

Stanley, D., Hughes, R.J., and Moore, R.J. 2014a. Microbiota of the chicken gastrointestinal tract: influence on health, productivity and disease. Appl. Microbiol. Biotechnol. 98: 4301-4310. doi:10.1007/s00253-014-5646-2.

Stanley, D., Wu, S.B., Rodgers, N., Swick, R.A., and Moore, R.J. $2014 b$. Differential responses of cecal microbiota to fishmeal, Eimeria and Clostridium perfringens in a necrotic enteritis challenge model in chickens. PLoS ONE, 9: e104739. doi:10.1371/ journal.pone.0104739.

Stokstad, E.L.R., and Jukes, T.H. 1950. Growth-promoting effect of aureomycin on turkey poults. Poult. Sci. 29: 611-612. doi:10.3382/ps.0290611.

Sugiharto, S., and Ranjitkar, S. 2019. Recent advances in fermented feeds towards improved broiler chicken performance, gastrointestinal tract microecology and immune responses: a review. Anim. Nutr. (Zhongguo xu mu shou yi xue hui), 5: 1-10.

Sugimoto, A., Maeda, A., Itto, K., and Arimoto, H. 2017. Deciphering the mode of action of cell wall-inhibiting antibiotics using metabolic labeling of growing peptidoglycan in Streptococcus pyogenes. Sci. Rep. 7: 1129. doi:10.1038/s41598017-01267-5. PMID:28442740.

Svihus, B. 2011. The gizzard: function, influence of diet structure and effects on nutrient availability. World's Poult. Sci. J. 67: 207-224. doi:10.1017/S0043933911000249.

Tellez, G., Latorre, J.D., Kuttappan, V.At., Kogut, M.H., Wolfenden, A., Hernandez-Velasco, X., et al. 2014. Utilization of rye as energy source affects bacterial translocation, intestinal viscosity, microbiota composition, and bone mineralization in broiler chickens. Front. Genet. 5: 339. doi:10.3389/fgene.2014.00339. PMID:25309584.

Tenson, T., Lovmar, M., and Ehrenberg, M. 2003. The mechanism of action of macrolides, lincosamides and streptogramin $B$ reveals the nascent peptide exit path in the ribosome. J. Mol. Biol. 330: 1005. doi:10.1016/S0022-2836(03) 00662-4. PMID:12860123.

Timbermont, L., Lanckriet, A., Dewulf, J., Nollet, N., Schwarzer, K., Haesebrouck, F., et al. 2010. Control of Clostridium perfringensinduced necrotic enteritis in broilers by target-released butyric acid, fatty acids and essential oils. Avian Pathol. 39: 117-121. doi:10.1080/03079451003610586. PMID:20390546.

Udumula, V., Ham, Y.W., Fosso, M.Y., Chan, K.Y., Rai, R., Zhang, J., et al. 2013. Investigation of antibacterial mode of action for traditional and amphiphilic aminoglycosides. Bioorg. Med. Chem. Lett. 23: 1671-1675. doi:10.1016/j.bmcl.2013. 01.073. PMID:23414844. 
van der Aar, P.J., Molist, F., and van der Klis, J.D. 2017. The central role of intestinal health on the effect of feed additives on feed intake in swine and poultry. Anim. Feed Sci. Technol. 233: 64-75. doi:10.1016/j.anifeedsci.2016.07.019.

Van Immerseel, F., Buck, J.D., Pasmans, F., Huyghebaert, G., Haesebrouck, F., and Ducatelle, R. 2004. Clostridium perfringens in poultry: an emerging threat for animal and public health. Avian Pathol. 33: 537-549. doi:10.1080/ 03079450400013162. PMID:15763720.

Van Immerseel, F., Boyen, F., Gantois, I., Timbermont, L., Bohez, L., Pasmans, F., et al. 2005. Supplementation of coated butyric acid in the feed reduces colonization and shedding of Salmonella in poultry. Poult. Sci. 84: 1851-1856. doi:10.1093/ps/84.12.1851. PMID:16479940.

Vieira, S., and Lima, I.L. 2005. Live performance, water intake and excreta characteristics of broilers fed all vegetable diets based on corn and soybean meal. Int. J. Poult. Sci. 4: 365-368. doi:10.3923/ijps.2005.365.368.

Vohra, P., Kratzer, F.H., and Joslyn, M.A. 1966. The growth depressing and toxic effects of tannins to chicks. Poult. Sci. 45: 135-142. doi:10.3382/ps.0450135. PMID:5905856.

Waititu, S.M., Yitbarek, A., Matini, E., Echeverry, H., Kiarie, E., Rodriguez-Lecompte, J.C., and Nyachoti, C.M. 2014. Effect of supplementing direct-fed microbials on broiler performance, nutrient digestibilities, and immune responses. Poult. Sci. 93: 625-635. doi:10.3382/ps.2013-03575. PMID:24604856.

Walk, C.L., and Rama Rao, S.V. 2020. Dietary phytate has a greater anti-nutrient effect on feed conversion ratio compared to body weight gain and greater doses of phytase are required to alleviate this effect as evidenced by prediction equations on growth performance, bone ash and phytate degradation in broilers. Poult. Sci. 99: 246-255. doi:10.3382/ ps/pez469. PMID:32416808.

Wang, L.C., Wen, C., Jiang, Z.Y., and Zhou, Y.M. 2012. Evaluation of the partial replacement of high-protein feedstuff with fermented soybean meal in broiler diets. J. Appl. Poult. Res. 21: 849-855. doi:10.3382/japr.2012-00563.

Wang, S., Peng, Q., Jia, H.M., Zeng, X.F., Zhu, J.L., Hou, C.L., et al. 2017. Prevention of Escherichia coli infection in broiler chickens with Lactobacillus plantarum B. Poult. Sci. 96: 2576-2586. doi:10.3382/ps/pex061. PMID:28482103.

Wang, X., Peebles, E.D., Morgan, T.W., Harkess, R.L., and Zhai, W. 2015. Protein source and nutrient density in the diets of male broilers from 8 to $21 \mathrm{~d}$ of age: effects on small intestine morphology. Poult. Sci. 94: 61-67. doi:10.3382/ps/peu019. PMID:25542197.

Wang, X., Peebles, E.D., Kiess, A.S., Wamsley, K.G.S., and Zhai, W. 2019a. Effects of coccidial vaccination and dietary antimicrobial alternatives on the growth performance, internal organ development, and intestinal morphology of Eimeriachallenged male broilers. Poult. Sci. 98: 2054-2065. doi:10.3382/ps/pey552.

Wang, X., Farnell, Y.Z., Peebles, E.D., Kiess, A.S., Wamsley, K.G., and Zhai, W. 2016. Effects of prebiotics, probiotics, and their combination on growth performance, small intestine morphology, and resident Lactobacillus of male broilers. Poult. Sci. 95: 1332-1340. doi:10.3382/ps/pew030. PMID:26944975.

Wang, X., Farnell, Y.Z., Kiess, A.S., Peebles, E.D., Wamsley, K.G.S., and Zhai, W. 2019b. Effects of Bacillus subtilis and coccidial vaccination on cecal microbial diversity and composition of Eimeria-challenged male broilers. Poult Sci. 98: 3839-3849.

Wealleans, A.L., Li, W., Romero, L.F., Mathis, G., and Lumpkins, B. 2017. Performance and cost-benefit improvements following supplementation with a combination of direct-fed microbials and enzymes to broiler chickens raised with or without ionophores. J. Appl. Poult. Res. 27: 23-32. doi:10.3382/japr/ pfx036.

Wilkie, D.C., Van Kessel, A.G., White, L.J., Laarveld, B., and Drew, M.D. 2005. Dietary amino acids affect intestinal Clostridium perfringens populations in broiler chickens. Can. J. of Anim. Sci. 85: 185-193. doi:10.4141/A04-070.

Wise, M.G., and Siragusa, G.R. 2007. Quantitative analysis of the intestinal bacterial community in one- to three-week-old commercially reared broiler chickens fed conventional or antibiotic-free vegetable-based diets. J. Appl. Microbiol. 102: 1138-1149. doi:10.1111/j.1365-2672.2006.03153.x. PMID:17381758.

Wisman, E.L., Boucher, R.V., and Callenbach, E.W. 1954. The influence of an antibiotic, animal protein, sex and rearing environment on chick growth. Poult. Sci. 33: 328-332. doi:10.3382/ps.0330328.

Woyengo, T.A., and Nyachoti, C.M. 2013. Review: Anti-nutritional effects of phytic acid in diets for pigs and poultry current knowledge and directions for future research. Can. J. Anim. Sci. 93: 9-21. doi:10.4141/cjas2012-017.

Woyengo, T.A., Kiarie, E., and Nyachoti, C.M. 2010. Metabolizable energy and standardized ileal digestible amino acid contents of expeller-extracted canola meal fed to broiler chicks. Poult. Sci. 89: 1182-1189. doi:10.3382/ ps.2009-00595. PMID:20460665.

Woyengo, T.A., Kiarie, E., and Nyachoti, C.M. 2011. Growth performance, organ weights, and blood parameters of broilers fed diets containing expeller-extracted canola meal. Poult. Sci. 90: 2520-2527. doi:10.3382/ps.2011-01436. PMID:22010237.

Xu, Z., Hu, C., Xia, M., Zhan, X., and Wang, M. 2003. Effects of dietary fructooligosaccharide on digestive enzyme activities, intestinal microflora and morphology of male broilers. Poult. Sci. 82: 1030-1036. doi:10.1093/ps/82.6.1030. PMID:12817461.

Yadav, S., and Jha, R. 2019. Strategies to modulate the intestinal microbiota and their effects on nutrient utilization, performance, and health of poultry. J. Anim. Sci. Biotechnol. 10: 2-11. doi:10.1186/s40104-018-0310-9. PMID:30651986.

Yan, F., Dibner, J.J., Knight, C.D., and Vazquez-Anon, M. 2017. Effect of carbohydrase and protease on growth performance and gut health of young broilers fed diets containing rye, wheat, and feather meal. Poult. Sci. 96: 817-828. doi:10.3382/ ps/pew300. PMID:27587727.

Yan, J., Zhou, B., Xi, Y., Huan, H., Li, M., Yu, J., et al. 2019. Fermented feed regulates growth performance and the cecal microbiota community in geese. Poult. Sci. 98: 4673-4684. doi:10.3382/ps/pez169. PMID:30993344.

Yang, Y., Iji, P.A., and Choct, M. 2009. Dietary modulation of gut microflora in broiler chickens: a review of the role of six kinds of alternatives to in-feed antibiotics. World's Poult. Sci. J. 65: 97-114. doi:10.1017/S0043933909000087.

Yun, W., Lee, D.H., Choi, Y.I., Kim, I.H., and Cho, J.H. 2017. Effects of supplementation of probiotics and prebiotics on growth performance, nutrient digestibility, organ weight, fecal microbiota, blood profile, and excreta noxious gas emissions in broilers. J. Appl. Poult. Res. 26: 584-592. doi:10.3382/japr/pfx033.

Zaefarian, F., Abdollahi, M.R., Cowieson, A., and Ravindran, V. 2019. Avian liver: the forgotten organ. Animals (Basel), 9: 63. doi:10.3390/ani9020063 [English].

Zanu, H.K., Keerqin, C., Kheravii, S.K., Morgan, N.K., Wu, S.B., Bedford, M.R., and Swick, R.A. 2020. Influence of meat and bone meal, phytase, and antibiotics on broiler chickens challenged with subclinical necrotic enteritis: 1. growth performance, intestinal $\mathrm{pH}$, apparent ileal digestibility, cecal microbiota, and tibial mineralization. Poult. Sci. 99: 1540-1550. doi:10.1016/j.psj.2019.11.021. PMID:32111321. 
Zhang, C., Zhao, X.H., Yang, L., Chen, X.Y., Jiang, R.S., Jin, S.H., and Geng, Z.Y. 2017. Resveratrol alleviates heat stressinduced impairment of intestinal morphology, microflora, and barrier integrity in broilers. Poult. Sci. 96: 4325-4332. doi:10.3382/ps/pex266. PMID:29053872.
Zhang, Q., Chen, X., Eicher, S.D., Ajuwon, K.M., and Applegate, T.J. 2016. Effect of threonine deficiency on intestinal integrity and immune response to feed withdrawal combined with coccidial vaccine challenge in broiler chicks. Br. J. Nutr. 116: 2030-2043. doi:10.1017/S0007114516003238. PMID:27993179. 